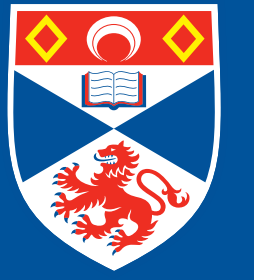

University of

St Andrews

Adaptive Learning and Labour D Market Dynamics

$+$

$r$

(D)

h

0

$\mapsto$

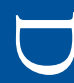

$\psi$

正

ט

३

ค.

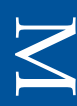

0

S

r

0

(D)

ก

0

吾

0

ß

$\mapsto$.

ค

$D$

ט

$\stackrel{\leftrightarrow}{\longleftarrow}$

os

$\mapsto$.

$\omega$
CDMA Working Paper Series No. 1408

10 Sep 2014

JEL Classification: E24, E25, E32, J64

Keywords: adaptive learning, bounded-rationality, search and matching frictions 


\title{
Adaptive Learning and Labour Market Dynamics*
}

\author{
Federico Di Pace \\ University of St Andrews \\ Kaushik Mitra \\ University of St Andrews \\ Shoujian Zhang ${ }^{\dagger}$ \\ University of St Andrews
}

September 10, 2014

\begin{abstract}
It is well known that the standard search and matching model with Rational Expectations (RE) is unable to generate amplification in unemployment and vacancies. We show that relaxing the $\mathrm{RE}$ assumption has the potential to provide a solution to this well known unemployment volatility puzzle. A model in which agents use Recursive Least Square algorithms to update their expectations as new information becomes available is presented. Firms choose vacancies by making infinite horizon forecasts over (un)employment rates, wages and interest rates at each point in time. Firms have much greater incentive for vacancy posting because of overoptimism about the discounted value of expected profits at the time a positive TFP shock hits the economy. The model with adaptive learning is able to match the relative volatility of labour market variables in US data and the properties of forecast errors of unemployment rates obtained from the Survey of Professional Forecasters.
\end{abstract}

Keywords: adaptive learning, bounded-rationality, search and matching frictions

JEL codes: E24, E25, E32, J64

\footnotetext{
${ }^{*}$ We would like to thank participants of the conference on "Expectations in Dynamic Macroeconomic Models" at the Bank of Finland (Helsinki), the 1st Birkbeck Centre of Applied Macroeconomics conference at Birkbeck College (London), the 20th Annual Computing in Economics and Finance Conference at the BI Norwegian Business School (Oslo), the 7th Conference of the Centre of Economic Growth and Business Cycles at the University of Manchester, the 2014 Asian Meeting of Econometric Society at the Academia Sinca (Taipei), 46th Annual Conference of the MMF at the University of Durham and seminar participants at the universities of Exeter and Cardiff and the Technical University of Vienna. We would especially like to thank William Branch, Stefano Eusepi, George Evans, Eric Gaus, Cars Hommes, Philipp Kircher, Albert Marcet, Paulo Santos Monteiro, Giovanni Melina, Ivan Petrella, Bruce Preston, Michael Reiter, Rajiv Sarin, Ron Smith, Tsvetomira Tsenova and our discussant Joseph Pearlman for useful comments and suggestions.

${ }^{\dagger}$ Corresponding Author: Shoujian Zhang. Address: School of Economics and Finance, Castlecliffe, The Scores, University of St Andrews, Fife KY16 9AR. E-mail: sz30@st-andrews.ac.uk
} 


\section{Introduction}

Shimer (2005) shows that the standard search and matching model, driven by Total Factor Productivity (TFP) innovations, has a hard time replicating the amplification of labour market variables, such as unemployment, vacancies and the measure of labour market tightness present in the US data. Under the common assumption that wages are negotiated through Nash bargaining every period, wages tend to absorb most of the productivity fluctuations, generating little amplification in profits per hire. A large number of studies have attempted to provide solutions to this unemployment volatility puzzle.

Two prominent solutions make relatively simple modifications to the standard search and matching model to generate greater amplification. The first approach proposed by Hall (2005) and Shimer (2005) introduces real wage rigidities. This means that, as wages cannot fully reflect productivity shifts, there is a further incentive for vacancy creation. ${ }^{1}$ The second popular approach by Hagedorn and Manovskii (2008) (henceforth, HM) carries out a simple calibration exercise that sets the value of non-market activity close to the value of search of the worker. ${ }^{2}$ These characterisations of the labour market have been criticised on the following grounds: a) microeconometric evidence by Pissarides (2009) and Haefke et al. (2013) are suggestive that wages for newly hired workers are cyclical and b) Costain and Reiter (2008) show that the implied elasticity of unemployment benefits relative to the unemployment rate arising from the calibration in HM is implausibly large relative to the data.

All these papers make the assumption that agents are endowed with rational expectations (RE). It has been argued, however, that there is an important divergence between the implied expectations in macroeconomic models with $\mathrm{RE}$ and the expectations drawn from the Survey of Professional Forecasters (SPF); see e.g. Slobodyan and Wouters (2012a), Slobodyan and Wouters (2012b), Milani (2011) and Del Negro and Eusepi (2011). These papers show that systematic errors in variables such as GDP and interest rates are evident in the SPF. One of the central variables in the search and matching model is the unemployment rate, which households and firms have to forecast. Figure 1 shows the one and four step-ahead forecast errors in unemployment rates obtained from the SPF. Note the systematic over/under-predictions of unemployment rates over the business cycle made in the surveys by professional forecasters. The figure shows that the forecast errors increase with the forecast horizon. The RE models discussed earlier are inconsistent with the survey data because agents do not make systematic errors.

Our paper investigates the role of expectations and expectation formation for the study of hiring decisions; it provides a solution to the unemployment volatility puzzle and matches the statistical properties of the forecast errors on unemployment found in the data. ${ }^{3}$ We develop a simple search and matching model where wages are negotiated period by period and the assumption of RE is replaced by subjective beliefs as in the adaptive

\footnotetext{
${ }^{1}$ Menzio (2005), Gertler et al. (2008), Christoffel and Kuester (2008), Gertler and Trigari (2009), Blanchard and Gali (2010) and Hertweck (2013), amongst others, extend this idea to a general equilibrium setting.

${ }^{2}$ The list of solutions to the unemployment volatility puzzle is not exhaustive; see Menzio and Shi (2011), Colciago and Rossi (2011), Di Pace and Faccini (2012), Alves (2012), Quadrini and Trigari (2008), Gomes (2011), Reiter (2007), Guerrieri (2008), Robin (2011), Petrosky-Nadeau (2013) and PetroskyNadeau and Wasmer (2013).

${ }^{3}$ The idea that expectations and expectational errors play a relevant role in explaining business cycle fluctuations is not new in economics and goes back to Pigou (1927) and Keynes (1936). See Eusepi and Preston (2011) for further discussion and list of references.
} 
Figure 1: Forecast Errors of Unemployment from SPF

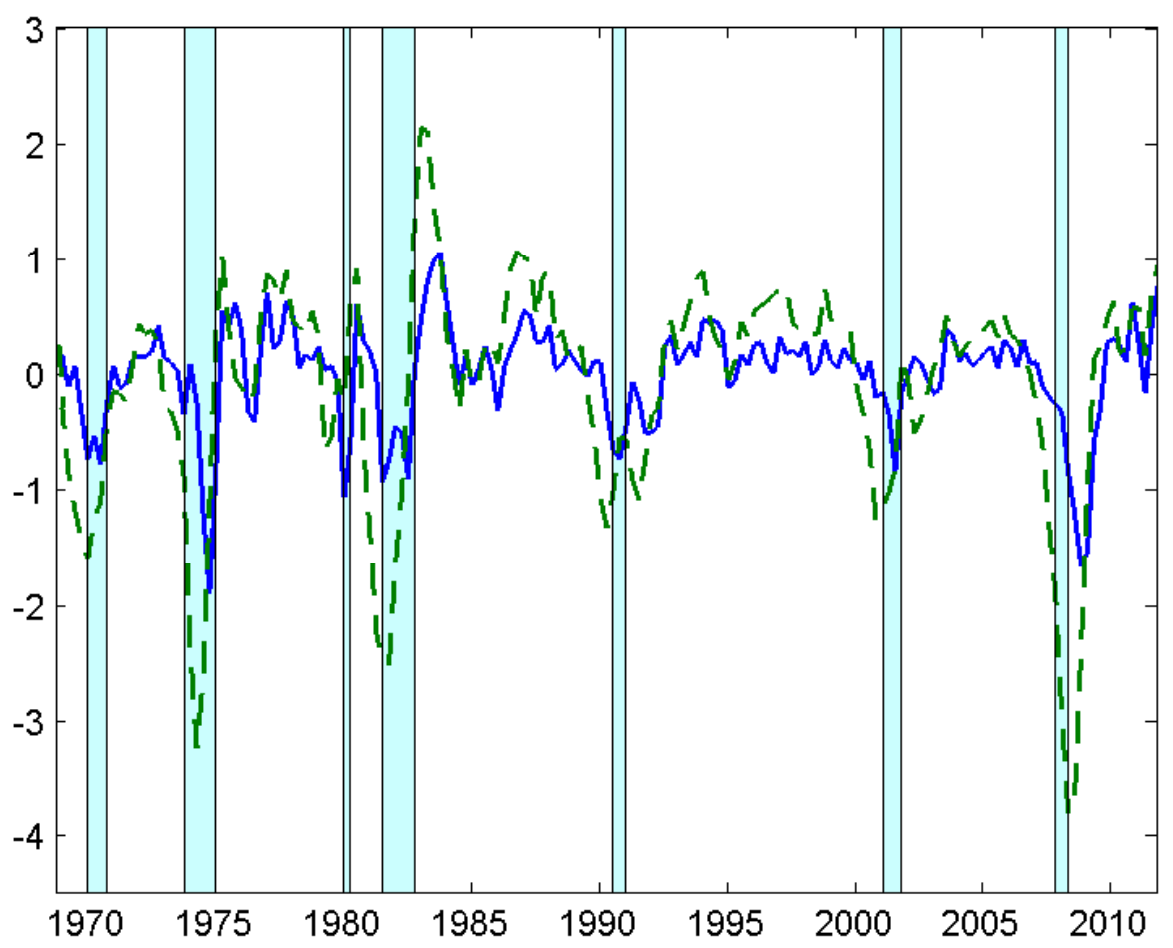

Notes. Forecast errors are expressed in unemployment percentage points, i.e. forecast unemployment rates minus actual unemployment rates. The solid and dotted lines denote one-step ahead and four-step ahead forecast errors of unemployment respectively. The graph shows that forecast errors increase as the time horizon of the forecast increases.

The bands show the NBER recession dates. The forecast errors are negative during recessions and positive during expansions.

learning literature. Unlike RE, firms and households form forecasts of unemployment, wages, profits and interest rates up to the infinite future to make consumption and hiring decisions using the (un)employment rate as a regressor. Firms in our model face a dynamic problem due to long-lasting employment relations modelled through search frictions. We assume that agents have incomplete knowledge about the structure of the economy in that they do not know the preferences and technologies of other agents in the economy and cannot infer the aggregate production function. Hiring decisions at the firm level depend crucially upon the perception of future profits per hire.

The assumption that economic agents engage in "learning" behavior has been incorporated into macroeconomic theory and used in a wide range of applications in macroeconomics, see Evans and Honkapohja (2001), Bullard and Mitra (2002), Evans and Honkapohja (2003), Preston (2005), Preston (2006), Evans and Honkapohja (2006) and Preston (2008). The standard adaptive learning approach treats economic agents like econometricians who estimate forecast rules, updating the parameter estimates over time as new data become available. Agents update their forecasting model, their forecasts of future variables and re-solve their dynamic optimization problem in order to make their decisions. In the context of infinite-horizon learning, agents solve dynamic optimization problems. ${ }^{4}$

\footnotetext{
${ }^{4}$ This differs from the Euler Equation (EE) approach used in the adaptive learning literature where agents use one-step ahead forecasts to formulate their current decisions.
} 
This learning approach can be viewed as a version of the anticipated utility approach formulated by Kreps (1998) and discussed in Sargent (1999b), and Cogley and Sargent (2008). ${ }^{5}$ For example, Eusepi and Preston (2011) use the anticipated utility approach within the context of the RBC model.

We show that the search and matching model with adaptive learning generates much more amplification in labour market variables compared to its RE counterpart. Unemployment and vacancies are 8 and 10 times more volatile than the corresponding measure of output, which is in line with US data; these numbers are in fact 18 and 20 times higher than those in the corresponding RE model. Our model successfully matches the statistical properties of forecast errors on unemployment data taken from the SPF. The volatility and cyclical behavior of unemployment forecast errors generated by this model match the data closely. This finding is in sharp contrast with the RE model and supports the type of perceived beliefs assumed in the learning model.

In the search and matching literature, the job creation condition represents the optimal decision rule for vacancy posting. Firms post vacancies until the expected marginal cost of posting a vacancy equals the marginal benefits of hiring an additional worker. The job creation condition can alternatively be written in terms of the (infinite) sum of expected future profits generated at the margin. ${ }^{6}$ Agents with incomplete knowledge about the structure of the economy tend to become optimistic after a positive TFP innovation and this in turn leads to more vacancy creation; the optimism is greater since firms forecast infinite periods ahead, which results in more vacancy creation and greater amplification.

The remainder paper is organised as follows. Section 2 describes the model environment. Section 3 presents the results of the model for the baseline calibration and explains the mechanism of amplification. Section 4 evaluates the quantitative performance of the model in terms of the forecast errors of unemployment and highlights the main differences between our approach and wage rigidities under RE beliefs. Section 5 analyses the robustness of the results to alternative beliefs and parameterisations. Section 6 presents the results for an alternative approach to learning, namely the Euler Equation approach. Section 7 concludes.

\section{Model}

We propose a simple model featuring labour market search and matching frictions as in Mortensen and Pissarides (1994) and a form of adaptive learning following Preston (2005) and Mitra et al. (2013). Our model economy is inhabited by two types of agents: households and firms. There is a representative household consisting of a continuum of workers that search for jobs if unemployed and work for firms if employed. Following Andolfatto (1996), we make the assumption of perfect risk sharing at the household level so that both employed and unemployed members of the household consume equal amounts. Firms post job vacancies and employ workers with a lag so as to produce final goods using

\footnotetext{
${ }^{5}$ In the anticipated utility approach recommended by Kreps, agents update their forecasts over time but do not take into account the fact that their forecasting model will be revised in future periods. This is a bounded rationality approach, since a full Bayesian approach would recognize the uncertainty in the parameters of the estimated forecasting model. However, as noted by Cogley and Sargent (2008), a full Bayesian approach in macroeconomic settings is typically "too complicated to be implemented," and thus the anticipated utility approach is an appealing implementation of bounded rationality.

${ }^{6}$ The solution to the model with RE beliefs is the same regardless of whether the decision rule for vacancies is specified recursively or as an infinite sum of future profits per hire.
} 
labour as the only input of production. Households consume the final goods supplied by firms. We assume that agents form their expectations by updating their beliefs as new information becomes available. Agents make Infinite Horizon (IH) forecasts about the future path of factor prices, unemployment and profits by running simple regressions that include the (un)employment rate as the regressor in order to make current decisions about consumption and vacancy posting.

\subsection{Labour Market}

The labour market is frictional in that, from the perspective of the firm, it is costly to post vacancies and, from the standpoint of workers, searching for jobs is a time consuming process. Every period firms create new vacancies, sought by unemployed workers who are continuously looking for new job opportunities. Following Shimer (2010), we assume that workers that are matched at time $t$ become productive at the beginning of next period, $t+1$. Worker-firm matches break up at the exogenous rate, $\rho \in(0,1)$. The aggregate number of matches, $m_{t}$, depends positively on both the unemployment rate, $u_{t}$, and aggregate vacancies, $v_{t}$. We assume that the matching process is guided by a matching function that exhibits constant returns to scale

$$
m\left(v_{t}, u_{t}\right)=\bar{m} v_{t}^{\sigma} u_{t}^{1-\sigma}
$$

where $\bar{m}$ denotes efficiency of the matching process, $\sigma$ the elasticity of the matching function with respect to aggregate vacancies and the unemployment rate is given by

$$
u_{t}=1-n_{t} .
$$

We define the measure of labour market tightness as

$$
\theta_{t}=v_{t} / u_{t}
$$

Due to the assumption of constant returns in the matching technology, we define the job finding rate as $m\left(v_{t}, u_{t}\right) / u_{t}=m\left(v_{t} / u_{t}, 1\right)=p\left(\theta_{t}\right)$ and the job filling rate as

$$
m\left(v_{t}, u_{t}\right) / v_{t}=m\left(1, u_{t} / v_{t}\right)=q\left(\theta_{t}\right) .
$$

Note that the job finding rate, $p\left(\theta_{t}\right)$, is increasing in the measure of labour market tightness and the job filling rate, $q\left(\theta_{t}\right)$, decreasing.

\subsection{Households}

In our model economy there is a large representative household consisting of a continuum of members in the unit interval that maximises her life-time utility

$$
\mathcal{H}\left(s_{t-1}, n_{t}\right)=\tilde{E}_{t} \sum_{s=t}^{\infty} \beta^{s-t} \mathcal{U}\left(c_{s}, n_{s}\right)
$$

where $\tilde{E}_{t}$ denotes the subjective expectation of the household at time $t$. $\mathcal{H}\left(s_{t-1}, n_{t}\right)$ denotes the value function of the household, which depends on last period savings and the period employment rate. The period utility of the representative household depends positively on consumption, $c_{t}$, and negatively on employment, $n_{t}$ and is defined by

$$
\mathcal{U}\left(c_{t}, n_{t}\right)=\log c_{t}-\chi n_{t}
$$


where $\chi>0$ is a parameter that captures the disutility of employment at the level of the household. The flow budget constraint reads

$$
s_{t}=w_{t} n_{t}+\pi_{t}+s_{t-1} r_{t-1}-c_{t},
$$

where $s_{t}$ denotes household savings at the end of period $t, r_{t}$ the real interest rate and $\pi_{t}=\int_{0}^{1} \pi_{t}^{f} d f$ aggregate profits (the are a continuum of firms indexed by $f \in[0,1]$ ), which are rebated to the household at the end of each period. The aggregate employment rate, $n_{t}$, is the sum of employment across firms, $n_{t}=\int_{0}^{1} n_{t}^{f} d f$ and $w_{t} n_{t}=\int_{0}^{1} w_{t}^{f} n_{t}^{f} d f$ the pooled wage bill. In addition, the employment rate at the household level evolves according to

$$
n_{t+1}=(1-\rho) n_{t}+u_{t} p\left(\theta_{t}\right) .
$$

The representative household chooses the level of consumption to maximise its life-time utility, (5), subject to the flow budget constraint, (6), and law of motion of employment, (7). The household's problem can be written in terms of the following Bellman equation

$$
\mathcal{H}\left(s_{t-1}, n_{t}\right)=\max _{c_{t}, s_{t}}\left[\log c_{t}-\chi n_{t}+\beta \tilde{E}_{t} \mathcal{H}\left(s_{t}, n_{t+1}\right)\right],
$$

together with the constraints (6) and (7). By combining the first order conditions with respect to $c_{t}$ and $s_{t}$, we obtain the standard Euler equation

$$
\frac{1}{c_{t}}=\beta r_{t} \tilde{E}_{t} \frac{1}{c_{t+1}} \text {. }
$$

This condition states that the household's marginal utility derived from consumption at time $t$ must equal the marginal utility of consumption derived at time $t+1$ expressed in terms of time $t$.

The envelope condition with respect to $n_{t}^{f}$ gives

$$
\frac{\partial \mathcal{H}\left(s_{t-1}, n_{t}\right)}{\partial n_{t}^{f}}=\frac{w_{t}^{f}}{c_{t}}-\chi+\beta\left[1-\rho-p\left(\theta_{t}\right)\right] \tilde{E}_{t} \frac{\partial \mathcal{H}\left(s_{t}, n_{t+1}\right)}{\partial n_{t+1}^{f}} .
$$

This condition states that the net marginal value of having a member of the household employed at firm $f$ is equal to the net flow value of employment, the difference between the wage and the utility cost of working, plus the net continuation value of employment.

By iterating forward the budget constraint, (6), and substituting for future values of savings, we can find an expression for consumption

$$
c_{t}+\tilde{E}_{t} \sum_{j=1}^{\infty} D_{t, t+j}^{-1} c_{t}=s_{t-1} r_{t-1}+w_{t} n_{t}+\pi_{t}+\tilde{E}_{t} \sum_{j=1}^{\infty} D_{t, t+j}^{-1}\left(w_{t+j} n_{t+j}+\pi_{t+j}\right),
$$

where $D_{t, t+j}=\prod_{i=0}^{j-1} r_{t+i}, j \geq 1$. We assume that the perceived transversality condition,

$$
\lim _{j \rightarrow \infty} \tilde{E}_{t} D_{t, t+j}^{-1} s_{t+j}=0
$$

holds. Using Euler equation (8), we can re-write the inter-temporal budget constraint as

$$
\frac{c_{t}}{1-\beta}=s_{t-1} r_{t-1}+w_{t} n_{t}+\pi_{t}+\tilde{E}_{t} \sum_{j=1}^{\infty} D_{t, t+j}^{-1}\left(w_{t+j} n_{t+j}+\pi_{t+j}\right) .
$$

This expression states that consumption depends on the sum of both perceived human and non-human wealth. 


\section{$2.3 \quad$ Firms}

Our model economy features a continuum of large firms of measure $f \in[0,1]$. Each firm $f$ employs labour to produce consumption goods using the following technology

$$
y_{t}^{f}=z_{t}^{f}\left(n_{t}^{f}\right)^{\alpha}
$$

where $y_{t}^{f}$ denotes output at the firm level, $n_{t}^{f}$ employment and $\alpha \in(0,1]$ the elasticity of output with respect to labour. In the baseline calibration, $\alpha$ is equal to 1 but we also examine the case where $\alpha$ is less than 1 . The productivity innovation $z_{t}^{f}$ follows an exogenous process given by

$$
\ln z_{t+1}^{f}=\varrho \ln z_{t}^{f}+\epsilon_{t+1}^{f} \quad \text { with } \quad \epsilon_{t}^{f} \sim N(0, \varsigma),
$$

where $\varrho \in(0,1)$ denotes the persistence of the technology process and $\epsilon_{t}^{f}$ is an i.i.d. innovation with mean zero and dispersion $\varsigma$. Although productivity is the same across all firms, individual firms do not know this to be true and, in effect, they view this as idiosyncratic.

Since posting vacancies is costly, period profits of firm $f, \pi_{t}^{f}$, at time $t$ may be written as

$$
\pi_{t}^{f}=z_{t}^{f}\left(n_{t}^{f}\right)^{\alpha}-w_{t}^{f} n_{t}^{f}-\mathcal{C}\left(v_{t}^{f}\right)
$$

where $v_{t}^{f}$ the number of job openings at the firm level and $\mathcal{C}(\cdot)$ is a convex and increasing vacancy cost function. The problem of each firm is to choose the process $v_{t}^{f}$ so as to maximise the present discounted value of expected profits, which can be written as

$$
\max _{v_{t+j}^{f}} \pi_{t}^{f}+\sum_{j=1}^{\infty} \tilde{E}_{t}^{f}\left[D_{t, t+j}^{-1} \pi_{t+j}^{f}\right] \quad \text { for } \quad j \geq 0
$$

subject to the law of motion of employment at the firm level

$$
n_{t+1}^{f}=(1-\rho) n_{t}^{f}+v_{t}^{f} q_{t} .
$$

The Bellman equation of this problem can be written as

$$
\mathcal{J}\left(n_{t}^{f}\right)=\max _{v_{t}^{f}}\left[\pi_{t}^{f}+r_{t}^{-1} \tilde{E}_{t}^{f} \mathcal{J}\left(n_{t+1}^{f}\right)\right]
$$

so that the problem of firm $f$ is to maximise this equation subject to (11) and (15). The first order condition with respect to $v_{t}^{f}$ reads

$$
\mathcal{C}^{\prime}\left(v_{t}^{f}\right)=q\left(\theta_{t}\right) r_{t}^{-1} \tilde{E}_{t}^{f} \mathcal{V}_{t+1}^{f}
$$

where $\mathcal{V}_{t}^{f}=\mathcal{J}^{\prime}\left(n_{t}^{f}\right)$ denotes the marginal value of having an additional worker employed at the firm. Equation (16) states that the marginal cost and benefit of posting a vacancy must be equal. The envelope condition with respect to $n_{t}^{f}$ is

$$
\mathcal{V}_{t}^{f}=\alpha z_{t}^{f}\left(n_{t}^{f}\right)^{\alpha-1}-w_{t}^{f}+(1-\rho) r_{t}^{-1} \tilde{E}_{t}^{f} \mathcal{V}_{t+1}^{f}
$$

This condition simply states that the value of having an additional worker employed at the firm must be equal to the flow value - the marginal productivity of employment net of wage costs - plus the continuation value of employment at the firm. 
By leading equation (17) one period forward, multiplying both sides of the expression by the stochastic discount factor, $\frac{1}{r_{t}}$, taking the expectation at time $t$ and combining the resulting expression with equation (16), we obtain the following job creation condition

$$
\frac{\mathcal{C}^{\prime}\left(v_{t}^{f}\right)}{q\left(\theta_{t}\right)}=r_{t}^{-1} \tilde{E}_{t}^{f}\left[\alpha z_{t+1}^{f}\left(n_{t+1}^{f}\right)^{\alpha-1}-w_{t+1}^{f}+(1-\rho) \frac{\mathcal{C}^{\prime}\left(v_{t+1}^{f}\right)}{q\left(\theta_{t+1}\right)}\right] .
$$

This condition is central to our analysis since it determines the optimal number of vacancies that firm $f$ would like to post. The expression simply states that the expected cost of posting a vacancy in the margin must be equal its benefit, which consists of expected profits and savings generated from the additional match. This way of formulating the firm's problem means that the choice of current vacancies is based on the forecast of future vacancies, which are in turn endogenous to the firm's decision making. Instead, in accordance with Preston (2005), we assume that firms make their current vacancy decisions based on variables that are exogenous to their decision making. So, we iterate forward equation (18) and get the following job creation condition ${ }^{7}$

$$
\frac{\mathcal{C}^{\prime}\left(v_{t}^{f}\right)}{q\left(\theta_{t}\right)}=\sum_{j=1}^{\infty}(1-\rho)^{j-1} \tilde{E}_{t}^{f} D_{t, t+j}^{-1}\left[\alpha z_{t+j}^{f}\left(n_{t+1}^{f}\right)^{\alpha-1}-w_{t+j}^{f}\right] .
$$

This condition states that the expected marginal cost of opening a vacancy must be equal to the perceived sum of future profits per additional hire. In addition, note that the firm's current decision is based on variables (such as $n_{t+1}$ and $w_{t}$ ) that are beyond their full control.

\subsection{Wage Negotiation}

Nash bargaining is used to determine wages for newly hired workers. The negotiated wage $w_{t}^{f}$ is set to maximise the joint surplus of a match between a worker and a firm,

$$
\arg \max _{w_{t}^{f}}\left[\frac{\partial \mathcal{H}\left(s_{t-1}, n_{t}\right)}{\partial n_{t}^{f}} c_{t}\right]^{\xi}\left(\mathcal{V}_{t}^{f}\right)^{1-\xi},
$$

where $\xi \in(0,1)$ denotes the workers' bargaining power or, alternatively, the share of surplus taken by the worker. ${ }^{8}$ Note that the household's surplus is the product between the marginal value of having a member of the household employed at firm $f$, defined in equation (9), and $c_{t}$ (the inverse of the marginal utility of consumption). Dividing $\frac{\partial \mathcal{H}\left(s_{t-1}, n_{t}\right)}{\partial n_{t}^{f}}$ by the marginal utility of consumption translates utility units of $\mathcal{H}$ in terms of goods. The first order condition of this problem then yields the standard sharing rule that characterises the optimal split of the aggregate surplus between a worker and a firm,

$$
(1-\xi)\left[\frac{\partial \mathcal{H}\left(s_{t-1}, n_{t}\right)}{\partial n_{t}^{f}} c_{t}\right]=\xi \mathcal{V}_{t}^{f}
$$

\footnotetext{
${ }^{7}$ Firm $f$ perceives that the transversality condition, $\lim _{j \rightarrow \infty}(1-\rho)^{j-1} \tilde{E}_{t}^{f} D_{t, t+j}^{-1}\left[\frac{\mathcal{C}^{\prime}\left(v_{t}^{f}\right)}{q\left(\theta_{t+j}\right)}\right]=0$, holds.

${ }^{8}$ The match values of the employment is specific to each member of the household and each employee of the firm.
} 
To derive an expression for the bargained wage, $w_{t}^{f}$, we assume that expression (42) holds for subjective expectations (see equation (43) in the appendix and the details therein). ${ }^{9}$ Furthermore, we assume that $\mathcal{C}\left(v_{t}^{f}\right)$ takes a linear form, $\mathcal{C}\left(v_{t}^{f}\right)=\kappa v_{t}^{f}$, as is standard in the literature, where $\kappa$ denotes the unitary vacancy cost. Thus, we obtain

$$
w_{t}^{f}=\xi \alpha z_{t}^{f}\left(n_{t}^{f}\right)^{\alpha-1}+\xi \kappa \theta_{t}+(1-\xi) \chi c_{t} .
$$

The bargained wage is a weighted average of the marginal product of employment plus the cost of replacing the worker and the opportunity cost of working.

\subsection{Aggregation and Market Clearing}

We make the assumption that households and firms share the same set of beliefs about the future. This assumption is reasonable because a) firms' employees are members of the household and firms are owned by the representative household, b) it is reasonable to assume that members of the households coordinate on expectations and c) wages are negotiated through a process of Nash bargaining between workers and firms. Productivity innovations, $z_{t}^{f}=z_{t}$, are the same across firms even though agents do know that to be true. The fact that we assume that expectations are homogeneous across households and firms, $\tilde{E}_{t}=\tilde{E}_{t}^{f}$, results in a symmetric equilibrium i.e., $n_{t}^{f}=n_{t}$ and $v_{t}^{f}=v_{t}$ for all $f$ and $t$.

The market clearing condition in the goods market can be obtained by summing up the period budget constraint and period profits (over $f$ )

$$
c_{t}+\kappa v_{t}=y_{t} .
$$

Imposing symmetry and following Mitra et al. (2013), we assume households use a consumption rule based on a linearisation of (10) around the steady state values $(\bar{c}, \bar{w}, \bar{n}, \bar{\pi}, \bar{r})$. We use the upper bar over the variable $x$ to denote the steady state value of variable $x$ and the hat over the variable $x$ to mean the deviations of the variable $x$ from its steady state value. The linearised household's behavior rule is given by

$$
\frac{\widehat{c}_{t}}{1-\beta}=\bar{r} \widehat{s}_{t-1}+\bar{s} \widehat{r}_{t-1}+\bar{n} \widehat{w}_{t}+\bar{w} \widehat{n}_{t}+\widehat{\pi}_{t}+\sum_{j=1}^{\infty} \beta^{j} \tilde{E}_{t}\left[\bar{n} \widehat{w}_{t+j}+\bar{w} \widehat{n}_{t+j}+\widehat{\pi}_{t+j}-(\bar{w} \bar{n}-\bar{\pi}) \beta \sum_{i=0}^{j-1} \widehat{r}_{t+i}\right] .
$$

We make the assumption that initial financial wealth is zero (by symmetry it will be zero in all future periods). It is then convenient to re-write (23) as

$$
\frac{\widehat{c}_{t}}{1-\beta}=\bar{n} \widehat{w}_{t}+\bar{w} \widehat{n}_{t}+\widehat{\pi}_{t}+\mathcal{S}_{w, t}^{H}+\mathcal{S}_{n, t}^{H}+\mathcal{S}_{\pi, t}^{H}-\mathcal{S}_{r, t}^{H}
$$

where

$$
\begin{aligned}
\mathcal{S}_{w, t}^{H} & =\sum_{j=1}^{\infty} \beta^{j} \bar{n} \tilde{E}_{t} \widehat{w}_{t+j}, & \mathcal{S}_{n, t}^{H} & =\sum_{j=1}^{\infty} \beta^{j} \bar{w} \tilde{E}_{t} \widehat{n}_{t+j}, \\
\mathcal{S}_{\pi, t}^{H} & =\sum_{j=1}^{\infty} \beta^{j} \tilde{E}_{t} \widehat{\pi}_{t+j}, & \mathcal{S}_{r, t}^{H} & =(\bar{w} \bar{n}+\bar{\pi}) \sum_{j=1}^{\infty}\left[\beta^{j+1} \tilde{E}_{t} \sum_{i=0}^{j-1} \widehat{r}_{t+i}\right] .
\end{aligned}
$$

\footnotetext{
${ }^{9}$ In line with what it is assumed under RE, this assumption makes it easy for the worker and the firm to agree on the bargained wage. This is a convenient simplifying assumption for our purpose. There may be alternative (more complex) ways of agreeing on the bargained wage, which we leave for future work.
} 
The $\mathcal{S}_{t}$ variables denote the discounted sums of future forecasts and are key for understanding the dynamic properties of the model that we shall discuss at a later stage. ${ }^{10}$

In line with the household problem, firms use a vacancy posting rule based on linearisation of equation (19) around steady state values of $\bar{w}, \bar{n}, \bar{q}, \bar{r}$ and $\bar{v}$. The firms' behavioral rule therefore reads

$$
\begin{aligned}
& \bar{\lambda}_{1} \bar{q} \widehat{v}_{t}-\left[\frac{\kappa}{\bar{q}^{2}}+\beta \bar{\lambda}_{1} \bar{v}\right] \widehat{q}_{t}=\beta \bar{\lambda}_{1}(1-\rho) \widehat{n}_{t}+\sum_{j=2}^{\infty}(1-\rho)^{j-1} \beta^{j} \tilde{E}_{t} \bar{\lambda}_{1} \widehat{n}_{t+j}+ \\
& +\sum_{j=1}^{\infty}(1-\rho)^{j-1} \beta^{j} \tilde{E}_{t}^{f}\left[\bar{\lambda}_{2} \widehat{z}_{t+j}-\widehat{w}_{t+j}-\left(\bar{z} \bar{\lambda}_{2}-\bar{w}\right) \beta \sum_{i=0}^{j-1} \widehat{r}_{t+i}\right],
\end{aligned}
$$

where $\bar{\lambda}_{1}=\alpha(\alpha-1) \bar{z} \bar{n}^{\alpha-2}$ and $\bar{\lambda}_{2}=\alpha \bar{n}^{\alpha-1} \cdot{ }^{11}$ We re-write $(25)$ as

$$
\bar{\lambda}_{1} \bar{q} \widehat{v}_{t}-\left[\frac{\kappa}{\bar{q}^{2}}+\beta \bar{\lambda}_{1} \bar{v}\right] \widehat{q}_{t}=\beta \bar{\lambda}_{1}(1-\rho) \widehat{n}_{t}+\mathcal{S}_{z, t}^{F}+\mathcal{S}_{n, t}^{F}-\mathcal{S}_{w, t}^{F}-\mathcal{S}_{r, t}^{F},
$$

where

$$
\begin{array}{ll}
\mathcal{S}_{z, t}^{F}=\sum_{j=1}^{\infty}(1-\rho)^{j-1} \beta^{j} \bar{\lambda}_{2} \tilde{E}_{t} \widehat{z}_{t+j}, & \mathcal{S}_{n, t}^{F}=\sum_{j=2}^{\infty}(1-\rho)^{j-1} \beta^{j} \bar{\lambda}_{1} \tilde{E}_{t} \widehat{n}_{t+j}, \\
\mathcal{S}_{w, t}^{F}=\sum_{j=1}^{\infty}(1-\rho)^{j-1} \beta^{j} \tilde{E}_{t} \widehat{w}_{t+j}, & \mathcal{S}_{r, t}^{F}=\left(\bar{z} \bar{\lambda}_{2}-\bar{w}\right) \sum_{j=1}^{\infty}(1-\rho)^{j-1} \beta^{j+1} \sum_{i=0}^{j-1} \tilde{E}_{t} \widehat{r}_{t+i} .
\end{array}
$$

The informational assumptions used in the derivation of equation (26) are detailed in Appendix B. We then linearise equation (21) around the steady state and then integrate it over $f$ in order to find an expression for the aggregate wage

$$
\widehat{w}_{t}=\xi \bar{\lambda}_{2} \widehat{z}_{t}+\xi \bar{\lambda}_{1} \widehat{n}_{t}+\xi \kappa \widehat{\theta}_{t}+(1-\xi) \chi \widehat{c}_{t} .
$$

Similarly, we linearise the unemployment rate (2), the production function (11), the profit function (13), the law of motion of employment (15), the goods market clearing condition (22) to get the following conditions

$$
\begin{gathered}
\widehat{n}_{t}+\widehat{u}_{t}=0, \\
\widehat{y}_{t}=\bar{n}^{\alpha} \widehat{z}_{t}+\bar{z} \alpha \bar{n}^{\alpha-1} \widehat{n}_{t}, \\
\widehat{\pi}_{t}=\bar{z} \alpha \bar{n}^{\alpha-1} \widehat{n}_{t}+\bar{n}^{\alpha} \widehat{z}_{t}-\bar{n} \widehat{w}_{t}-\bar{w} \widehat{n}_{t}-\kappa \widehat{v}_{t}, \\
\widehat{n}_{t+1}=(1-\rho) \widehat{n}_{t}+\bar{v} \widehat{q}_{t}+\bar{q} \widehat{v}_{t}, .
\end{gathered}
$$

and

$$
\widehat{c}_{t}+\kappa \widehat{v}_{t}=\widehat{y}_{t} .
$$

We also linearise equations (3), (4) and (12) to get

$$
\begin{gathered}
\bar{\theta} \widehat{u}_{t}+\bar{u} \widehat{\theta}_{t}=\widehat{v}_{t}, \\
\widehat{q}_{t}=(\sigma-1) m \bar{\theta}^{\sigma-2} \widehat{\theta}_{t}
\end{gathered}
$$

\footnotetext{
${ }^{10}$ Note that in the sums $\mathcal{S}_{n, t}^{H}$ and $\mathcal{S}_{r, t}^{H}$ the variables $\widehat{r}_{t}$ and $\widehat{n}_{t+1}$ are known to the agents when they form their time $t$ decisions; however, we retain these terms inside the expectations for expositional purposes.

${ }^{11}$ Note that $\bar{\lambda}_{1}$ becomes 0 and $\bar{\lambda}_{2}$ becomes 1 when the production function exhibits constant returns to scale. For brevity, we denote $\widehat{q}_{t}$ by the absolute deviation of $q\left(\theta_{t}\right)$.
} 
and

$$
\widehat{z}_{t+1}=\varrho \widehat{z}_{t}+\epsilon_{t+1} .
$$

We assume all firms have the same productivity, hence we drop the subscript $f$ from now on as in equation (12). A stationary competitive equilibrium is a set of stationary processes $\widehat{c}_{t}, \widehat{y}_{t}, \widehat{v}_{t}, \widehat{w}_{t}, \widehat{r}_{t}, \widehat{\pi}_{t}, \widehat{n}_{t+1}, \widehat{u}_{t}, \widehat{\theta}_{t}, \widehat{q}_{t}$ that, given the exogenous stochastic process $\left\{z_{t}\right\}_{j=t}^{\infty}$ and the initial condition $n_{t}$, satisfy the system of equations consisting of (24) and (26)-(35).

\subsection{Learning}

We deviate from rational expectations and assume instead that agents forecast the values of variables of interest based on their own beliefs by running simple regressions and behaving as if they were econometricians. We assume that agents have complete knowledge about the steady state as implicit in (23) and (25) but incomplete knowledge about the structure of the economy. Agents do not fully understand how the productivity shocks influence the future wage bargaining processes. They also believe that productivity shocks may shift the steady state of the model and, hence, include an intercept term in their regression equations. Agents only observe their own objectives and constraints but have no knowledge about other agents' preferences and beliefs. Hence, they do not know that their decisions are identical to those of other agents.

Agents' beliefs over the behaviour of $n_{t}, r_{t}, w_{t}$, and $\pi_{t}$ are expressed in levels rather than in deviations from their steady state values. In particular, we assume that agents have the following Perceived Law of Motions (PLMs)

$$
x_{t}=b_{x}+a_{x n} n_{t}+\mu_{x t}, \quad \text { for } \quad x_{t}=\left\{n_{t+1}, \pi_{t}, w_{t}, r_{t}\right\} .
$$

where $\mu_{x t}$ are white noise processes. Note that this belief system depends on the employment rate, $n_{t}$, or alternatively the unemployment rate $u_{t}$, since $n_{t}=1-u_{t}$. In terms of specification of the belief system, the key difference with the rational expectation solution is that the variable $\widehat{z}_{t}$ is omitted. ${ }^{12}$ Under the proposed belief system the economy converges to a restricted perception equilibrium as in Sargent (1999a), Evans and Honkapohja (2001), Cho et al. (2002a), Branch (2004) and Branch and Evans (2006a) that is different from the RE equilibrium.

This is a reasonable assumption because unlike unemployment data, which is usually publicly observed in monthly frequencies, aggregate productivity innovations are harder to quantify. Such productivity innovations are usually inferred as residuals of a regression model which include factors of production as independent variables. Firms know their individual production function and observe their own productivity, but do not know the aggregate production function and, hence, cannot infer aggregate productivity. Furthermore, if aggregate productivity depends on individual processes unobserved by firms, then they cannot work out the effect of these processes on unemployment, interest rates,

\footnotetext{
${ }^{12}$ The fully-specified beliefs consist of simply adding the TFP innovation as an additional explanatory variable to the above regressions. Hence, the fully-specified model consist of the following set of equations

$$
x_{t}=b_{x}+a_{x n} n_{t}+a_{x z} \widehat{z}_{t}+\eta_{x t}, \quad \text { for } \quad x_{t}=\left\{n_{t+1}, \pi_{t}, w_{t}, r_{t}\right\}
$$

where $\eta_{x t}$ are white noise processes. This set of correctly specified beliefs (like RE beliefs) is not able to provide a solution to the unemployment volatility puzzle or to generate forecast error properties which match the survey data.
} 
wages and profits. This approach is a reduced-form representation of a more complicated problem in which firms make inferences in the presence of multiple imperfectly observed disturbances. See Eusepi and Preston (2011), p. 2851, for a more detailed discussion on this point.

Agents update their beliefs over time by revising the value of parameters using a Recursive Least Square algorithm. At the beginning of each period, agents inherit the parameters of their belief system from the previous period, make forecasts and compute the present discounted sums that allows them to make consumption and vacancy posting decisions at every point in time. The interest rate is determined simultaneously with all other agents' economic decisions to clear both goods and labour markets and the wage rate through the process of Nash bargaining between each firm and worker pair. At the end of each period, agents are informed about factor prices, (un)employment and profits and they then update their beliefs accordingly in the following period.

Let $A_{t}=\left(\begin{array}{llll}A_{n, t} & A_{w, t} & A_{r, t} & A_{\pi, t}\end{array}\right)$, where $A_{n, t}=\left(\begin{array}{ll}b_{n} & a_{n n}\end{array}\right)^{\prime}, A_{w, t}=\left(\begin{array}{ll}b_{w} & a_{w n}\end{array}\right)^{\prime}, A_{r, t}=$ $\left(\begin{array}{ll}b_{r} & a_{r n}\end{array}\right)^{\prime}, A_{\pi, t}=\left(\begin{array}{ll}b_{\pi} & a_{\pi n}\end{array}\right)^{\prime}, C_{t}=\left(\begin{array}{llll}n_{t} & w_{t-1} & r_{t-1} & \pi_{t-1}\end{array}\right)^{\prime}$ and $B_{t}=\left(\begin{array}{ll}1 & n_{t}\end{array}\right)^{\prime}$. We assume that agents use a constant gain Recursive Least Square (RLS) algorithm to update their beliefs

$$
\begin{aligned}
& A_{t}=A_{t-1}+\gamma R_{t}^{-1} B_{t-1}\left(C_{t}-A_{t-1}^{\prime} B_{t-1}\right)^{\prime}, \\
& R_{t}=R_{t-1}+\gamma\left(B_{t-1} B_{t-1}^{\prime}-R_{t-1}\right),
\end{aligned}
$$

where $\gamma \in(0,1)$ denotes the constant gain learning parameter. Constant-gain least squares is widely used in the adaptive learning literature because it weights recent data more heavily. See for example Sargent (1999b), Cho et al. (2002b), McGough (2006), Orphanides and Williams (2007), Ellison and Yates (2007), Huang et al. (2009), CarcelesPoveda and Giannitsarou (2008), Eusepi and Preston (2011) and Milani (2011).

For the parameter estimation, agents use data up to $t-1$ including $n_{t}$, which is pre-determined and known at the beginning of time $t$. Expectations are formed at the beginning of time $t$. However, agents' decisions depend on contemporaneous variables.

\section{$3 \quad$ Numerical Results}

\subsection{Calibration}

We set the values of parameters in the model following a standard calibration exercise. First, we choose some parameter values using a priori information. Second, the choice of remaining parameters ensures that the stationary equilibrium of the model matches a number of stylised facts as observed in the post-WWII US economy. As is standard in the literature, a period in our model corresponds to a month in the data.

The parameters set using a priori information are the subjective discount factor, $\beta$, the exogenous separation rate, $\rho$, the worker's bargaining power, $\xi$, and the elasticity of the matching function with respect to vacancies, $\sigma$. The value of $\beta$ is set to 0.996 , which implies an annual real interest rate of about 4\%. The value of $\rho$ is calibrated to 0.033 in order to match the evidence that jobs last on average two and a half years as estimated in Davis et al. (1996). We set the value of $\sigma$ at 0.5 in line with the literature. This value lies within the plausible interval of $[0.5,0.7]$ as surveyed by Petrongolo and Pissarides (2001). 
Table 1: Calibrated Parameter Values - Monthly

\begin{tabular}{lcc}
\hline \hline Description & Parameter & Value \\
\hline Discount Factor & $\beta$ & 0.996 \\
Parameter in the Utility Function & $\chi$ & 0.528 \\
Efficiency of the Matching Technology & $\bar{m}$ & 0.566 \\
Elasticity of the Matching Function & $\sigma$ & 0.5 \\
Bargaining Power & $\xi$ & 0.5 \\
Unitary Vacancy Posting Cost & $\kappa$ & 0.192 \\
Separation Rate & $\rho$ & 0.033 \\
Elasticity of Output w.r.t. Employment & $\alpha$ & 1 \\
Productivity Level & $\bar{z}$ & 1 \\
Persistence of Productivity Shocks & $\varrho$ & 0.98 \\
St. Dev. of Productivity Shocks & $\varsigma$ & 0.01 \\
Gain Parameter & $\gamma$ & 0.002 \\
\hline
\end{tabular}

In order to facilitate comparability with the existing literature, $\xi$ is chosen to be 0.5 . (The choice of the values of $\sigma$ and $\xi$ ensures that Hosios (1990) condition is met.) The elasticity of output with respect to employment, $\alpha$, is set to 1. Following Shimer (2010), we choose the persistence of the technology shock, $\varrho$, to be 0.98 and the standard deviation of the productivity shocks to be 0.01 .

The remaining three labour market parameters, namely $\kappa, \bar{m}$ and $\chi$, are set to match:

i) a vacancy cost to output ratio of 0.01 in line with Andolfatto (1996), Gertler and Trigari (2009) and Blanchard and Gali (2010);

ii) a vacancy filling rate of $27.8 \%$ as estimated by Shimer (2005), which is consistent with a quarterly rate of $70 \%$ as in Trigari (2006) and den Haan et al. (2000);

iii) an unemployment rate of $6 \%$, which corresponds with the standard ILO definition of unemployment for the post-WWII US average.

The resulting replacement ratio - computed as the disutility of work over the wage and the marginal utility of consumption $(\chi c / w)$ - is equal to $83 \%$, which is above the value of $70 \%$ suggested by Mortensen and Nagypal (2007). According to a study by Hagedorn and Manovskii (2008), a total replacement ratio of around 95\% can generate labour market fluctuations that are in line with the empirical evidence. Their study argues that, if the outside option of the worker is high (this happens when both $\xi$ is low and the replacement ratio high), then the size of firm's steady state profits is small and can generate greater amplification in labour market variables. The replacement ratio in their study is equal to the value of non-market activity that includes both unemployment subsidies and the value of leisure. Costain and Reiter (2008) have criticised this calibration because it gives rise to excessive sensitivity of unemployment to unemployment benefits. ${ }^{13}$ The resulting replacement ratio ensures that our results are not driven by the Hagedorn and Manovskii effect. This will become clear once we examine the amplification properties of the model under RE beliefs. Table 1 provides a summary of the parameters used in the baseline calibration of our hypothetical model economy.

\footnotetext{
${ }^{13}$ The introduction of unemployment benefits in our model is likely to generate greater amplification like they do in models with RE beliefs.
} 
We choose the gain parameter in the learning algorithm to be $\gamma=0.002$ (equivalent to a value of 0.006 in the corresponding quarterly model), which implies that agents use past data to update their beliefs for roughly 42 years $(1 / 0.002=500$ months $)$. There is lack of consensus in the learning literature concerning the constant gain parameter, which ranges from 0.002 to 0.035 at quarterly frequencies. See for example Eusepi and Preston (2011), Branch and Evans (2006b), Milani (2007) and Orphanides and Williams (2007). The value chosen for this parameter is relatively small because we exclude policy considerations (for example as in Mitra et al. (2013) where a higher gain parameter is used) but lies within the range of parameters suggested in the literature. We conduct a robustness exercise later with different values of the gain parameter.

\subsection{US Data}

In this section we compare the main statistical properties of the simulated labour market series generated from the model with the corresponding series in the US data, in particular focusing on second moments. It is standard practice, in one-worker-one-firm models, to compute the standard deviations of labour market data relative to productivity, but, in large-firm models, the standard measures that capture the volatilities of data are typically divided by the corresponding measure of output. Since our model is a large-firm model, we take the latter approach to compute relative standard deviations.

The seasonally adjusted series of (un)employment is taken from the Bureau of Labour Statistics (BLS). As a proxy for vacancies we merge the seasonally adjusted help-wanted advertising index released by the Conference Board with the vacancy series calculated by Barnichon (2010). Aggregate output is measured as seasonally adjusted real GDP, which is drawn from the National Income and Product Account (NIPA) tables 1.1.6 and 1.1.5. All data series are quarterly and cover the period ranging from 1951Q1 to 2011Q4. Table 2 summarises the main cyclical properties of the logged detrended series. ${ }^{14}$

One of the most salient features in the data is the high cyclicality of unemployment, vacancies and labour market tightness as reported in Table 2 . In particular, both vacancies and unemployment are about 9.25 and 8.65 times more volatile than the aggregate output respectively. Moreover, the measure of labour market tightness is around 17.51 times more volatile than output. ${ }^{15}$

\subsection{Simulation results}

We simulate a search and matching model endowing the agents first with RE beliefs, then with adaptive learning and compare the two scenarios. Table 3 shows that the RE model generates very little amplification in labour market variables.

We initiate the simulation of our baseline model from the RE solution and then generate a series for 3,932 periods using the learning algorithm previously stated. ${ }^{16}$ We then discard the first 3,200 periods and keep the remaining 732 observations, which correspond to 61 years of data, so as to guarantee that the simulated series are free from any transitional dynamic considerations. We then repeat this procedure 2,500 times to ensure that our results are not contaminated by single random draws. Since our model is calibrated

\footnotetext{
${ }^{14}$ We use the Hodrick-Prescott filter with a smoothing parameter of 1600 to detrend the series.

${ }^{15}$ Another well known stylised fact in labour market dynamics is the negative relationship between vacancies and unemployment, also known as the Beveridge curve.

${ }^{16}$ We employ a projection facility in agents' regression equations but they are never used in our simulations.
} 
Table 2: Summary Statistics, quarterly US data.

\begin{tabular}{cccccccc}
\hline \hline & & $y$ & $n$ & $v$ & $u$ & $\theta$ & $c$ \\
\hline$\sigma_{x} / \sigma_{y}$ & & 1 & 0.55 & 9.25 & 8.65 & 17.51 & 0.79 \\
\hline Autocorrelation & & 0.81 & 0.89 & 0.90 & 0.88 & 0.90 & 0.80 \\
\hline Correlation matrix & $y$ & 1 & 0.81 & 0.85 & -0.79 & 0.84 & 0.86 \\
& $n$ & - & 1 & 0.91 & -0.97 & 0.96 & 0.66 \\
& $v$ & - & - & 1 & -0.91 & 0.98 & 0.71 \\
& $u$ & - & - & - & 1 & -0.98 & -0.62 \\
& $\theta$ & - & - & - & - & 1 & 0.68 \\
& $c$ & - & - & - & - & - & 1 \\
\hline
\end{tabular}

Notes. Standard Deviations and correlations in this table correspond to quarterly series, detrended using a Hodrick-Prescott filter with smoothing parameter of 1600.

Table 3: Summary Statistics, RE model

\begin{tabular}{cccccccc}
\hline \hline & & $y$ & $n$ & $v$ & $u$ & $\theta$ & $c$ \\
\hline$\sigma_{\hat{x}} / \sigma_{\hat{y}}$ & & 1 & 0.03 & 0.50 & 0.43 & 0.91 & 1.01 \\
\hline Autocorrelation & & 0.96 & 0.97 & 0.92 & 0.97 & 0.96 & 0.96 \\
\hline \multirow{4}{*}{ Correlation matrix } & $y$ & 1 & 0.99 & 0.99 & -0.99 & 1.00 & 1.00 \\
& $n$ & - & 1 & 0.96 & -1.00 & 0.99 & 0.99 \\
& $v$ & - & - & 1 & -0.96 & 0.99 & 0.99 \\
& $\theta$ & - & - & - & 1 & -0.99 & -0.99 \\
& $\theta$ & - & - & - & - & 1 & 1.00 \\
& $c$ & - & - & - & - & - & 1 \\
\hline
\end{tabular}

Notes. Relative standard deviations, autocorrelations and correlation coefficients in this table correspond to the quarterly simulated series expressed in percentage deviations from the steady state values.

for monthly frequencies and the US data is reported only in quarterly frequencies, we then convert the simulated series from monthly frequencies into quarterly frequencies. Finally, we transform the simulated series from deviations into percentage deviations by simply dividing by the corresponding steady state values.

Table 4 reports the statistical properties of the simulated series of interest under learning in the baseline scenario. The table shows that the search and matching model with learning can replicate the second moments of the US labour market remarkably well. Vacancies and unemployment are about 10.31 and 7.83 times more volatile than output respectively. We find that, although the model underestimates the relative volatility of unemployment and overestimates the relative volatility of vacancies (only) slightly, the general performance of the model in terms the amplification is highly satisfactory. This can be seen by comparing the relative standard deviation of labour market tightness; it is 17.89 in the model as opposed to 17.51 in the data. Thus, we see that our simple learning model has the potential to generate substantial amplification in vacancies, unemployment and the measure of labour market tightness. ${ }^{17}$

\footnotetext{
${ }^{17}$ However, we find that vacancies display a slightly lower persistence relative to the data. See Table 4.
} 
Table 4: Summary Statistics, Learning Model

\begin{tabular}{|c|c|c|c|c|c|c|c|}
\hline & & $y$ & 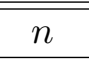 & 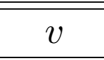 & 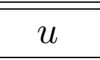 & $\overline{\bar{\theta}}$ & 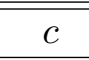 \\
\hline$\sigma_{\hat{x}} / \sigma_{\hat{y}}$ & & 1 & 0.50 & 10.31 & 7.83 & 17.19 & 0.93 \\
\hline Autocorrelation & & 0.95 & 0.93 & 0.57 & 0.93 & 0.85 & 0.94 \\
\hline \multirow{6}{*}{ Correlation matrix } & $y$ & 1 & 0.94 & 0.76 & -0.94 & 0.88 & 1.00 \\
\hline & $n$ & - & 1 & 0.79 & -1.00 & 0.93 & 0.93 \\
\hline & $v$ & - & - & 1 & -0.79 & 0.96 & 0.71 \\
\hline & $u$ & - & - & - & 1 & -0.93 & -0.93 \\
\hline & $\theta$ & - & - & - & - & 1 & 0.85 \\
\hline & $c$ & - & - & - & - & - & 1 \\
\hline
\end{tabular}

Notes. Relative standard deviations, autocorrelations and correlation coefficients in this table correspond to the quarterly simulated series expressed in percentage deviations from the steady state values.

\subsection{Mechanism of Amplification}

In this section we study the transmission mechanism of TFP innovations to disentangle the source of amplification in the model. We first describe the transmission mechanism of shocks in the standard search and matching model with RE beliefs in order to understand the source of amplification in the learning model.

A TFP shock has well-understood implications in the standard search and matching model. A positive TFP innovation, $\epsilon_{t}$, shifts the production frontier and the labour demand schedule, by increasing labour productivity, which raises marginal profits per hire. Since wages in the standard model are flexible and negotiated through the process of Nash bargaining, the shift in technology also increases current and future wages per hire, which in turn reduces marginal profits. Firms would like to hire in the margin so long as expected profits per hire increase. In the RE model, however, wages tend to absorb most of the increase in productivity, leading to little incentive for vacancy creation. ${ }^{18}$

To gain intuition we consider the job creation condition, equation (26), in linearised form. ${ }^{19}$ For simplicity, we set the value of $\alpha$ equal to 1 , in which case $\bar{\lambda}_{1}=0$ and $\bar{\lambda}_{2}=1$ and, hence, $\mathcal{S}_{n, t}^{F}=0$. Thus, we have

$$
-\frac{\kappa}{\bar{q}^{2}} \widehat{q}_{t}=\mathcal{S}_{t}^{F} \equiv \mathcal{S}_{z, t}^{F}-\mathcal{S}_{w, t}^{F}-\mathcal{S}_{r, t}^{F}
$$

We ignore the term involving $\mathcal{S}_{r, t}^{F}$ in equation (36), since it plays a minor role, and re-write equation (36) as

$$
-\frac{\widehat{q}_{t}}{\bar{q}} \approx \frac{\bar{q}}{\kappa} \tilde{E}_{t} \sum_{j=1}^{\infty}(1-\rho)^{j-1} \beta^{j}\left[\widehat{z}_{t+j}-\widehat{w}_{t+j}\right] \equiv \frac{\bar{q}}{\kappa}\left(\mathcal{S}_{z, t}^{F}-\mathcal{S}_{w, t}^{F}\right) .
$$

\footnotetext{
${ }^{18} \mathrm{As}$ mentioned in the introduction, amplification in labour market variables can be generated by introducing real wage rigidities into the standard RE model. However, this approach has been criticised e.g. by Pissarides (2009) and Haefke et al. (2013) on the grounds that micro-econometric evidence is suggestive that wages for newly hired workers are highly cyclical. As will be clear, our learning model provides an alternative explanation for amplification without introducing real wage rigidities.

${ }^{19}$ The vacancy creation condition in the standard model is written in terms of one-step ahead forecasts about profits per hire and labour market conditions. As shown earlier, this condition is equivalent to forecasting future profits per hire to infinity.
} 
This expression shows that the job filling rate is determined by the presented discounted value of marginal revenues of hiring net of marginal costs. The same equation holds under RE with $\tilde{E}_{t}$ replaced by objective expectations, $E_{t}$. The RE solution of the linearised model can be written in terms of absolute deviations of the variables from their steady state values

$$
\begin{aligned}
\widehat{n}_{t+1} & =\bar{a}_{n n} \widehat{n}_{t}+\bar{a}_{n z} \widehat{z}_{t}, \\
\widehat{w}_{t} & =\bar{a}_{w n} \widehat{n}_{t}+\bar{a}_{w z} \widehat{z}_{t}, \\
\widehat{z}_{t+1} & =\varrho \widehat{z}_{t}+\epsilon_{t+1},
\end{aligned}
$$

where $\bar{a}_{x y}$ denotes the elasticities of variable $x$ with respect to $y$, where $x=\{n, w\}$ and $y=\{n, z\} .{ }^{20}$ For the baseline calibration, $0<\bar{a}_{x y}<1$ for all possible combinations of $x$ and $y$. Using these solutions in (37) gives

$$
-\frac{\widehat{q}_{t}}{\bar{q}} \approx \frac{\bar{\beta} q}{\kappa}\left(\bar{\phi}_{1} \widehat{z}_{t}-\bar{\phi}_{2} \widehat{n}_{t}-\bar{\phi}_{3} \widehat{z}_{t}\right)
$$

where $\bar{\phi}_{1}=\frac{\varrho}{1-\beta(1-\rho) \varrho}, \bar{\phi}_{2}=\frac{\bar{a}_{w n} \bar{a}_{n n}}{1-\beta(1-\rho) \bar{a}_{n n}}$ and $\bar{\phi}_{3}=\frac{\bar{a}_{w n} \bar{a}_{n z}(1-\beta(1-\rho) \rho)+\varrho \bar{a}_{w z}\left(1-\beta(1-\rho) \bar{a}_{n n}\right)}{\left[1-\beta(1-\rho) \bar{a}_{n n}\right][1-\beta(1-\rho) \varrho]}$. This expression provides the crucial insight into the lack of amplification under RE. At the outset, note that the vacancy posting decision does not respond to employment because $\widehat{n}_{t}$ is a pre-determined variable; it is next period employment that affects vacancy posting. There is a direct effect from productivity innovations, $\widehat{z}_{t}$, to the vacancy posting decision through shifts in future returns from employment (term $\bar{\phi}_{1} \widehat{z}_{t}$ in equation (22), which corresponds to the first infinite sum in (37)) and an indirect effect from productivity innovations through shifts in future wage costs (the terms $\bar{\phi}_{2} \widehat{n}_{t}$ and $\bar{\phi}_{3} \widehat{z}_{t}$ in equation (22), which correspond to the second infinite sum in (37)). For the baseline calibration, it can be shown that $\bar{\phi}_{1}$ and $\bar{\phi}_{3}$ in equation (22) are very close to each other, which implies that productivity innovations have little impact on the present discounted value of profits. ${ }^{21}$ In other words, when firms correctly forecast future revenues and wages per hire, the variability of profits per hire is dampened because wages are flexible and they tend to absorb a large part of the productivity innovation. As a result, the RE model is unable to generate sufficient amplification in vacancies.

We now turn to an explanation of the dynamics under learning. We first note that under RE firms have knowledge of the general equilibrium restrictions that determine future wages and employment; in particular, that a positive productivity shock leads to higher wages and employment in the future. Under learning, on the other hand, firms are not aware of these general equilibrium restrictions, i.e. that future wages and employment will be higher due to the shock. In the learning model agents are unable to understand the implications of future wage negotiations and instead run simple regression models to forecast future wages. Although wages are flexible, the expectation of wages displays inertia. A TFP innovation affects equation (27) directly but has no direct impact on the expectation of wages; it only affects the expectation of wages through changes in future employment. In effect, firms underestimate the present discounted value of expected wages and, hence, overestimate the present discounted value of expected profits. This overoptimism of profits leads to more job creation under learning vis-a-vis RE.

\footnotetext{
${ }^{20}$ Note that this solution is equivalent to the solution in levels so long as $\bar{n}=\frac{b_{n}}{1-a_{n n}}$ and $\bar{x}=b_{x}+\frac{a_{x n} b_{n}}{1-a_{x n}}$ for $x=\{\pi, w, r\}$.

${ }^{21}$ The baseline calibration ensures that our results are not driven by the HM strategy; see Hagedorn and Manovskii (2008).
} 
The job creation condition under learning is given by

$$
-\frac{\widehat{q}_{t}}{\bar{q}} \approx \frac{\beta \bar{q}}{\kappa}\left(\phi_{1} \widehat{z}_{t}-\phi_{2} \widehat{n}_{t}\right)
$$

where $\phi_{1}=\bar{\phi}_{1}$ and $\phi_{2}=\frac{a_{w n} a_{n n}}{1-\beta(1-\rho) a_{n n}}$. It is worth noting that the elasticities, $\bar{a}_{x y}$, under RE differ considerably to the elasticities, $a_{x y}$, under learning. Compared to the RE solution, the extent of overoptimism in profits is (approximately) given by the term $\bar{\phi}_{3} \widehat{z}_{t}$ in equation (22). We note that asymptotically the estimated steady state values of endogenous variables, such as wages, employment, are the same as the RE values; i.e. they are asymptotically unbiased. ${ }^{22}$

The introduction of unemployment and high persistence of the productivity process can help explain the larger internal propagation mechanism of the learning model. The high persistence of the TFP innovation in the job creation condition increases on impact the discount factor of future revenues per hire (due to the presence of $\varrho$ in equation (39)) relative to the discount factor associated with future wages (due to the presence of $a_{n n}$ in equation (39)). This leads firms to overestimate the present discounted value of profits per hire, which then translates into further incentives for vacancy creation. Thus, the labour market becomes tighter and the job filling rate falls after a TFP innovation, which then increases the expected costs of vacancy posting. More vacancies in equilibrium translate into higher employment and production.

The system is, however, self-referential in the sense that beliefs about the future path of wages tend to have an impact on future vacancy creation and employment. Shifts in current economic conditions in turn affect the belief system. From the job creation condition, it follows that the updated values of $a_{w n}$ and $a_{n n}$ have an impact on job creation through shifts in employment in subsequent periods. The parameters estimates evolve slowly over time in response to new information. A positive productivity innovation leads to an increase in employment, which in turn raises the costs of future employment relations. In addition, a productivity innovation tends to increase the estimated values of $a_{n n}$ and $a_{w n}$ in subsequent periods, increasing expected wage costs. The updated forecasts of future wages exhibit large variation from period to period due to the fact that $a_{n n}$ and $a_{w n}$ are updated as new information becomes available. Larger variation in the forecast of wages in turn generates larger amplification in profits per hire.

As firms observe only their own productivity, they can accurately forecast the future marginal returns of employment. The productivity innovations are perceived as idiosyncratic innovations rather than as aggregate innovations since firms do not know that they

\footnotetext{
${ }^{22}$ We have experimented with an alternative belief system in which agents forecasts wages by running regressions using employment as the only regressor but they forecast all other variables of interest using employment and the TFP innovation as regressors; in other words, the mis-specification is only with regards to wages. The belief system is

$$
\widehat{x}_{t}=a_{n n} \widehat{n}_{t}+a_{n z} \widehat{z}_{t}+\mu_{x t} \quad \text { for } \quad x_{t}=\left\{\widehat{n}_{t+1}, \widehat{\pi}_{t}, \widehat{r}_{t}\right\} \quad \text { and } \quad \widehat{w}_{t}=a_{w n} \widehat{n}_{t}+\mu_{w t} .
$$

The job creation condition under this scenario can be written in terms of the belief system (ignoring the term $\mathcal{S}_{r, t}^{F}$ as before)

$$
-\frac{\widehat{q}_{t}}{\bar{q}} \approx \frac{\bar{\beta} q}{\kappa}\left(\phi_{1} \widehat{z}_{t}-\phi_{2} \widehat{n}_{t}-\phi_{3} \widehat{z}_{t}\right),
$$

where $\phi_{1}$ and $\phi_{2}$ have the same expressions. Note however that there is an additional term $\phi_{3}=$ $\frac{a_{w n} a_{n z}}{\left[1-\beta(1-\rho) a_{n n}\right]}$, which reduces expected profits per hire. This means that productivity innovations have a lower impact on vacancy creation because agents are able to better forecast future employment and, hence, make more accurate wage forecasts.
} 
are identical to each other. Firms do not use aggregate productivity and instead use the publicly observed unemployment rate to forecast future wages as per their perceived beliefs about the economy. Firms gradually revise their future wage expectations upwards whenever they observe a fall in the unemployment rate.

\subsection{Impulse Responses}

In this sub-section, we study how the labour market variables respond to TFP innovation and compare the dynamics under RE and learning. Following Eusepi and Preston (2011), the impulse responses of the learning model are computed by simulating the model twice over $3,200+120$ periods by hitting them with the same sequence of productivity shocks. The first 3,200 periods ensure convergence towards the restricted perception equilibrium. We add to the first simulation a positive 1\% standard deviation (productivity) shock in period 3,201 and compute the impulse responses as the difference between the two resulting set of impulse responses from period 3,201 onwards. This experiment is then repeated 2,500 times. We then report the mean impulse responses of the variables of interest. Furthermore, we convert the simulated series into quarterly frequencies and plot the percentage deviations of the variables from the deterministic steady state values.

Figure 2 shows the impulse responses of aggregate output, (un)employment, vacancies, labour market tightness and the job filling rate to this positive TFP innovation under learning and RE. The impulse responses under RE display negligible amplification relative to the baseline model. As discussed earlier, firms endowed with RE beliefs correctly understand the general equilibrium restrictions on future wages so that expected wages tend to absorb most of the productivity increase. As a consequence, unemployment, vacancies and the measure of labour market tightness respond only marginally to a TFP innovation under RE.

Very distinct dynamic responses are observed under learning to a positive TFP innovation. Following a positive technology shock, the incentive for vacancy creation increases sharply, leading to more employment and a sharp fall in unemployment. As the labour market tightens and the job finding probability falls, the marginal cost of posting a vacancy tends to increase, matching the rise in the marginal benefit associated with vacancy posting. The response in unemployment is, however, sluggish relative to the response in vacancies given that unemployment is pre-determined and displays higher persistence. As discussed earlier, a productivity innovation leads to overoptimism and more vacancy creation. Under RE the dynamics of all variables are monotonically converging to the steady state while under learning we observe over and under-shooting of variables as they converge to the steady state.

To disentangle the results under learning, we plot the infinite sums in (36). As shown earlier, the infinite sum $\mathcal{S}_{t}^{F}$ in equation (36), i.e. the present discounted value of profits, responds much more strongly under the learning model relative to RE. Figure 3 decomposes this infinite sum, $\mathcal{S}_{t}^{F}$, into three components, $\mathcal{S}_{z, t}^{F}, \mathcal{S}_{w, t}^{F}$ and $\mathcal{S}_{r, t}^{F}$. Note that $\mathcal{S}_{z, t}^{F}$ is the same under RE and learning and, hence, the lines overlap. This figure shows that the order of magnitude of $\mathcal{S}_{r, t}^{F}$ is much smaller relative to that of $\mathcal{S}_{z, t}^{F}$ and $\mathcal{S}_{w, t}^{F}$ (note the vertical access of $\mathcal{S}_{r, t}^{F}$ ); the stochastic discount factor displays little variation relative to the other two infinite sums. Note that the size of the responses of these sums under RE are of equal magnitudes, which explains the negligible amplification generated by the standard RE search and matching model. In sharp contrast, the magnitude of the response of $\mathcal{S}_{z, t}^{F}$ is much higher than that of $\mathcal{S}_{w, t}^{F}$ after a TFP innovation under learning. The difference 
Figure 2: Impulse responses: Labour Market Variables
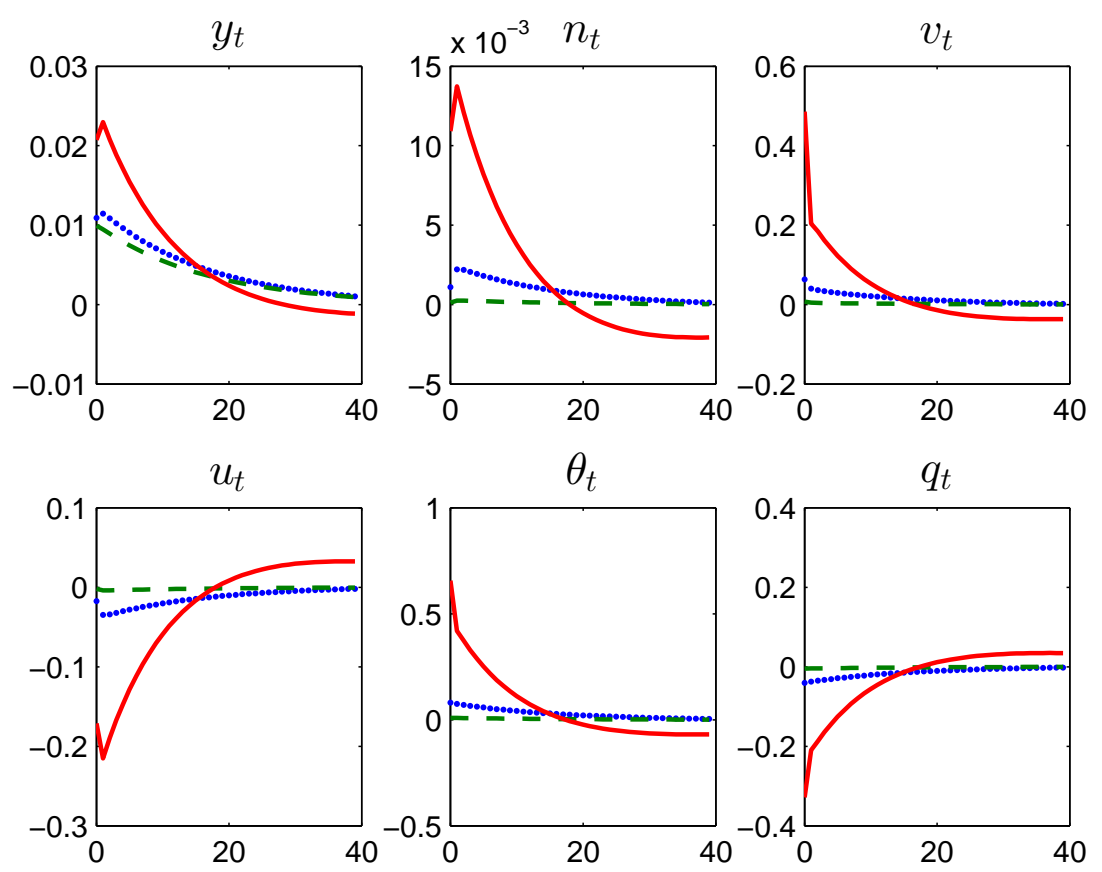

Notes. Impulse responses to a one percent standard deviation (productivity) shock are measured along the vertical axes in percentage deviations from the steady state. The horizontal axes display the number of quarters after the shock. The solid line shows the impulse responses under IH learning (baseline model), the dotted lines denote the impulse responses under EE learning and the dashed lines the impulse responses under RE.

between $\mathcal{S}_{z, t}^{F}$ and $\mathcal{S}_{w, t}^{F}$ explains the strong amplification mechanism of the learning model and the high variation in vacancy posting on impact.

Figure 2 shows that the learning model increases the internal propagation mechanism of the model. In particular, the response of output in our model significantly exceeds the TFP innovation on impact. In contrast, under RE the response of output is approximately the same as the TFP innovation, which is a feature of the unemployment volatility puzzle. The reason behind the greater response in output under the learning model has to do with a larger increase in employment. The dynamics of consumption (not plotted in the figure) is qualitatively the same as that of output.

\section{Forecast Properties of the Model}

The forecast of future variables plays a key role in our model since both households and firms must form their expectations of future (un)employment rates, wages, interest rates and profits so as to make consumption and job posting choices. As shown in Section 3 , agents' forecasts are central for matching the amplification of labour market variables with the data. In this section we, therefore, analyse how well the statistical properties of the unemployment forecasts generated by our model compared with those in the data as reported by the Survey of Professional Forecasters.

As indicated by the PLMs, agents' forecast all future variables based on their expectations of future (un)employment rates. We can, therefore, compare the performance of forecast errors of future employment rates generated by the model relative to the data. 
Figure 3: Impulse responses: Infinite Sums in the Job Creation Condition
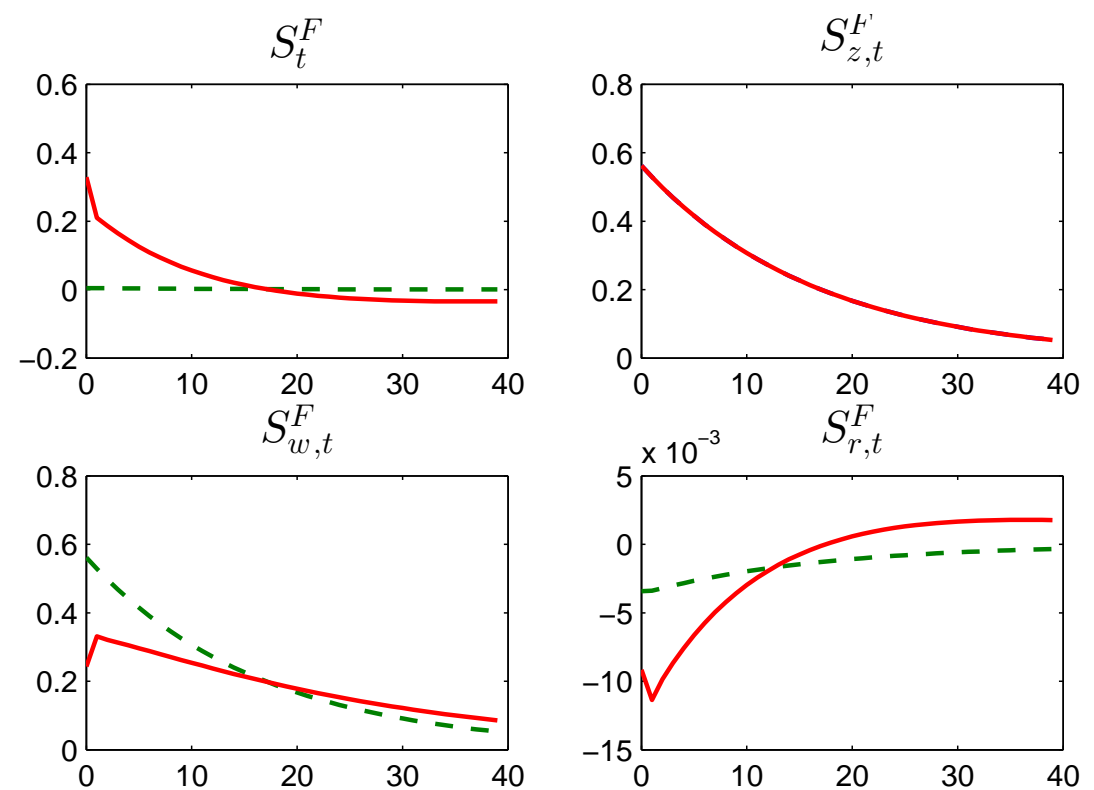

Notes. Impulse responses to a one percent standard deviation (productivity) shock are measured along the vertical axes in percentage deviations from the steady state (note that the infinite sums have been multiplied by $\bar{q} \kappa$ to obtain the percentage deviations). Horizontal axes display the number of quarters after the shock. The solid lines show the impulse responses with IH learning (baseline) and the dashed lines denote the impulse responses under RE. Note that the infinite sum of revenues per hire are equal under learning and RE and, hence, they overlap in the plot of $\mathcal{S}_{z, t}^{F}$.

We take the quarterly forecasts of unemployment rates from the Survey of Professional Forecasters, which are collected by the Federal Reserve Bank of Philadelphia. Questionnaires are sent to the individual forecasters to carry out their expert forecasts at the end of the first month of the each quarter and individual forecasts are released towards the end of the second month of each quarter. Forecast data are available from 1968Q4 to 2011Q4 and both mean and median of forecasts are reported up to four quarters ahead. We compute the forecast errors by removing from the forecast data the actual realisation of the unemployment rates up to four periods ahead using BLS data. We then divide the resulting error by the average unemployment rate over the period, which is equal to $6.26 \%$ in order to express the data in terms of percentage deviations.

Table 5 reports the statistical properties of the forecast errors, including their relative volatility with respect to the HP series of output, the autocorrelation of the forecast errors and their correlation with output growth and the first difference of unemployment. We find that the forecast errors are much more volatile relative to output over the 4quarter horizon. The table shows that the one quarter-ahead forecast errors is almost 4.9 times more volatile than output. In addition, the quarterly forecast errors display high serial correlation, which is stronger as the time horizon of the forecast increases. Furthermore, over the business cycle, the forecast errors on unemployment rate are all pro-cyclical, which means agents tend to over-predict unemployment during expansions and under-predict it in recessions.

Table 5 also reports the statistical properties of the simulated forecast errors expressed in percentage deviations from the steady state unemployment rate under both RE and learning. The simulation methods used here are essentially the same as described in 
Table 5: Forecast Properties

\begin{tabular}{lccccc}
\hline \hline & & $F E_{t}^{Q 1}$ & $F E_{t}^{Q 2}$ & $F E_{t}^{Q 3}$ & $F E_{t}^{Q 4}$ \\
\hline \multirow{4}{*}{ Data } & $\sigma_{x} / \sigma_{y}$ & 4.86 & 6.70 & 8.59 & 10.44 \\
& $\rho\left(x_{t}, x_{t-1}\right)$ & 0.69 & 0.78 & 0.84 & 0.88 \\
& $\rho\left(x_{t}, \Delta u_{t}\right)$ & -0.75 & -0.60 & -0.51 & -0.43 \\
& $\rho\left(x_{t}, \Delta y_{t}\right)$ & 0.53 & 0.51 & 0.48 & 0.44 \\
\hline \multirow{4}{*}{ RE } & $\sigma_{x} / \sigma_{y}$ & 0.04 & 0.13 & 0.19 & 0.23 \\
& $\rho\left(x_{t}, x_{t-1}\right)$ & 0.06 & 0.24 & 0.58 & 0.72 \\
& $\rho\left(x_{t}, \Delta u_{t}\right)$ & -0.06 & -0.04 & -0.02 & 0.00 \\
& $\rho\left(x_{t}, \Delta y_{t}\right)$ & 0.08 & 0.10 & 0.07 & 0.05 \\
\hline \multirow{4}{*}{ Learning } & $\sigma_{x} / \sigma_{y}$ & 1.81 & 6.55 & 8.13 & 8.87 \\
& $\rho\left(x_{t}, x_{t-1}\right)$ & 0.39 & 0.66 & 0.84 & 0.87 \\
& $\rho\left(x_{t}, \Delta u_{t}\right)$ & -0.48 & -0.34 & -0.29 & -0.26 \\
& $\rho\left(x_{t}, \Delta y_{t}\right)$ & 0.56 & 0.42 & 0.34 & 0.30 \\
\hline
\end{tabular}

Notes. The term $\rho\left(x_{1}, x_{2}\right)$ stands for the correlation coefficient between variables $x_{1}$ and $x_{2}$. Data from Survey of Professional Forecasters. Forecast errors are defined as $F E_{t}^{Q j}=\frac{E_{t} u_{t+j}-u_{t+j}}{\bar{u}} \quad$ for $j=$ $1,2,3,4$, where $\bar{u}$ is the average unemployment rate over the period 1968Q4-2011Q4.

previous subsection, with the exception that the simulation horizon after convergence is now set to be 512 (months) - matching the time span of the available forecast data - and the mean of the unemployment rate set to $6.26 \%$. The simulated monthly forecast errors series are also converted to quarterly frequencies by simple averaging. It follows from the table that the performance of the RE model at matching the statistical properties of the forecast errors in the data is rather poor. The RE model predicts a very low relative volatility of the forecast errors, negligible autocorrelation and no pro-cyclicality. The baseline model performs better relative to the RE model in matching the statistical properties of the forecast errors. The learning model generates a sizeable relative volatility of the forecast errors, strictly positive autocorrelations, positive correlation with the output growth and negative correlation with the first difference of unemployment. The one-quarter ahead forecast errors are more serially correlated and display a greater deal of amplification in the data relative to what the learning model suggests.

\subsection{Does Wage Rigidity under RE match Forecast Errors?}

As mentioned in Section 1, the introduction of wage rigidity in the standard search and matching model under $\mathrm{RE}$ is able generate greater amplification in labour market variables. ${ }^{23}$ The rationale behind this result is simple: if quantities display little amplification after TFP innovations, fixing prices have the potential to generate the expected results. We now show that while the introduction of wage rigidities leads to higher volatility under $\mathrm{RE}$ as is well known in the literature, it does not lead to properties of forecast errors that match those of the SPF.

In accordance with Hall (2005) a wage norm or social consensus can be perceived as a rule to select an equilibrium for the wage within the bargaining set. We assume that

\footnotetext{
${ }^{23}$ Recall that this assumption has, nevertheless, been criticised by Pissarides (2009) and Haefke et al. (2013) on the grounds that microeconometric evidence suggests that wages for newly hired workers are cyclical.
} 
Table 6: Wage Rigidities under RE

\begin{tabular}{|c|c|c|c|c|c|c|}
\hline \multicolumn{7}{|c|}{ Relative Volatilities } \\
\hline & $y$ & $n$ & $v$ & $u$ & $\theta$ & $c$ \\
\hline$\sigma_{x} / \sigma_{y}$ & 1 & 0.38 & 6.98 & 6.00 & 12.84 & 0.94 \\
\hline \multicolumn{7}{|c|}{ Forecast Properties } \\
\hline & & & $F E_{t}^{Q 1}$ & $F E_{t}^{Q 2}$ & $F E_{t}^{Q 3}$ & $F E_{t}^{Q 4}$ \\
\hline & $\sigma_{x} / \sigma_{y}$ & & 0.03 & 0.10 & 0.15 & 0.18 \\
\hline & $\rho\left(x_{t}, x_{t-1}\right)$ & & -0.05 & 0.09 & 0.04 & 0.07 \\
\hline & $\rho\left(x_{t}, \Delta u_{t}\right)$ & & 0.01 & -0.06 & -0.07 & -0.07 \\
\hline & $\rho\left(x_{t}, \Delta y_{t}\right)$ & & 0.00 & 0.00 & 0.01 & 0.01 \\
\hline
\end{tabular}

Notes. Relative standard deviations this table correspond to the quarterly simulated series expressed in percentage deviations from the steady state values in the RE model featuring wage rigidities. Forecast errors $F E_{t}^{Q j}$ for $j=\{1,2,3,4\}$ as defined in Table 5.

the wage is given by a weighted average of the steady state wage and the negotiated wage under the Nash protocol in equation (27)

$$
\widehat{w}_{t}=\omega \bar{w}+(1-\omega) \widehat{w}_{t}^{N a s h},
$$

where $\widehat{w}_{t}^{\text {Nash }}$ is the bargained wage in $(27)$ and $\omega \in(0,1)$ denotes the wage rigidity parameter. We set the value of $\omega$ to 0.7 in line with Blanchard and Gali (2010).

Table 6 reports the relevant statistics for this model. Amplification in labour market variables is much improved relative to the RE model with flexible wages (though it is less than the benchmark learning model for this parameterisation of $\omega$ ). Unlike the benchmark learning model with flexible wages, wages here do not fully absorb the contemporaneous TFP innovations. The forecast errors are way out of line with the data, like in the standard RE model, since agents understand fully the general equilibrium restrictions implied by the model. Unlike the introduction of real wage rigidities under RE, our baseline learning model features a pro-cyclical wage arrangement. Wages in the baseline model fully reflect productivity innovations but, due to the fact that firms are unaware of the general equilibrium restrictions, the wage forecast display high inertia. The belief system in the baseline model is able to both solve the unemployment volatility puzzle and to match the properties of the forecast errors with the data.

\section{Robustness}

In this section, we investigate the robustness of our results for the baseline learning model with regards to alternative beliefs and parameterisations.

\subsection{Alternative Beliefs}

Another possible standard way for forming beliefs is of the AR(1) class. There is evidence in experimental studies, i.e. Hommes et al. (2005), Heemeijer et al. (2009) and Hommes and Zhu (2014), that agents form expectations of variables using past values of the same variable to forecast future variables of interest to them. 
Table 7: AR(1) Beliefs

\begin{tabular}{|c|c|c|c|c|c|c|}
\hline \multicolumn{7}{|c|}{ Relative Volatilities } \\
\hline & $y$ & $n$ & $v$ & $u$ & $\theta$ & $c$ \\
\hline$\sigma_{x} / \sigma_{y}$ & 1 & 0.54 & 10.86 & 8.39 & 18.37 & 0.93 \\
\hline \multicolumn{7}{|c|}{ Forecast Properties } \\
\hline & & & $F E_{t}^{Q 1}$ & $F E_{t}^{Q 2}$ & $F E_{t}^{Q 3}$ & $F E_{t}^{Q 4}$ \\
\hline & $\sigma_{x} / \sigma_{y}$ & & 3.92 & 5.97 & 7.05 & 7.63 \\
\hline & $\rho\left(x_{t}, x_{t-1}\right)$ & & 0.47 & 0.78 & 0.85 & 0.89 \\
\hline & $\rho\left(x_{t}, \Delta u_{t}\right)$ & & -0.16 & -0.21 & -0.19 & -0.17 \\
\hline & $\rho\left(x_{t}, \Delta y_{t}\right)$ & & 0.27 & 0.29 & 0.26 & 0.23 \\
\hline
\end{tabular}

Notes. Relative standard deviations this table correspond to the quarterly simulated series expressed in percentage deviations from the steady state values under $A R(1)$ beliefs. Forecast errors $F E_{t}^{Q j}$ for $j=\{1,2,3,4\}$ as defined in 5 .

The PLMs of agents are then of the following form

$$
x_{t}=b_{x}+a_{x} x_{t-1}+\psi_{x t} \quad \text { for } \quad x_{t}=\left\{n_{t+1}, \pi_{t}, w_{t}, r_{t}\right\},
$$

where $\psi_{x t}$ are white noise processes. Let $A_{x, t}=\left(\begin{array}{ll}b_{x} & a_{x}\end{array}\right)^{\prime}$ and $B_{x t}=\left(\begin{array}{ll}1 & x_{t-1}\end{array}\right)^{\prime}$. We assume that agents use a constant gain Recursive Least Square (RLS) algorithm to update their beliefs

$$
\begin{aligned}
& A_{x t}=A_{x t-1}+\gamma R_{x t}^{-1} B_{x t-1}\left(x_{t-1}-A_{x t-1}^{\prime} B_{x t-1}\right)^{\prime}, \\
& R_{x t}=R_{x t-1}+\gamma\left(B_{x t-1} B_{x t-1}^{\prime}-R_{x t-1}\right) .
\end{aligned}
$$

As opposed to the baseline model, the perceptions of agents with regards to $\pi_{t}, w_{t}$ and $r_{t}$ now depend on their past values (rather than employment).

We find that the learning model with $\mathrm{AR}(1)$ beliefs continues to have good properties in terms of amplification and forecast errors. Table 7 shows that the model displays amplification in labour market variables that match closely the US data (compare with Table 2). The key to understanding the dynamics of unemployment and vacancies is the forecast of wages. In the baseline model, agents forecast wages by running regressions on the employment rate. Since employment is a pre-determined variable, the expectations of wages display a high degree of inertia and, therefore, a TPF innovation leads to an increase in profits and more vacancy creation. A similar mechanism is at work when agents are endowed with $\mathrm{AR}(1)$ beliefs, this time operating through regressing directly on wages that are pre-determined. The relative volatility of the quarterly one-step ahead forecast is more in line with the data (and more than twice as much as the baseline model) but from the second quarter onwards the relative volatilities of the forecast errors are (slightly) lower than the baseline model, which in turn is lower than the data. The autocorrelations of forecast errors are closer to the data than the baseline model (especially for the first two periods). However, compared to the baseline model, the correlations with regards to changes in unemployment and output are further away from the data.

While in the baseline model forecasting unemployment is important for vacancy creation, in the model with $\mathrm{AR}(1)$ beliefs, wage forecast data is the key driver of unemployment dynamics. Our key aim in the analysis is to match the forecast errors in unemployment and the baseline model does this directly. Contrariwise, with $\mathrm{AR}(1)$ beliefs, it is 
the forecast errors in wage which drives unemployment dynamics and ideally we would like to compare the forecast errors of wages in the model with the relevant data but unfortunately wage data is not available in the SPF. Hence, we use the forecast errors of unemployment as a proxy.

\subsection{Alternative Parameterisation}

In this subsection we look at the sensitivity of our results to alternative parameterisations of our model. We first consider a calibration of the model with decreasing returns to scale in labour and then consider two values of the constant gain parameter.

The calibration of our baseline model assumes constant returns to scale in labour. We carry out an alternative calibration exercise to check whether our results depend on the choice of the elasticity of output with respect to employment. In line with models featuring physical capital, we set the value of $\alpha$ equal to 0.67 and simulate the model under this new parameterisation. The main conceptual difference with the baseline calibration is that the demand curve under decreasing returns to labour is downward sloping rather than constant. However, this alternative calibration does not change the transmission mechanism of TFP innovations because the effect of employment in the job creation condition, as stated in equation (26), has only a minor impact on the present discounted value of profits per hire. We find that the results from this simulation are in line with the simulations of our baseline model. The main difference is that setting a lower value of $\alpha$ reduces the replacement ratio to $0.79 \%$ and therefore reduces the amplification of labour market variables only slightly. Table 8 shows that the labour market variables still display a great deal of variation.

We then consider two alternative values of the gain parameter so as to check the sensitivity of our results to the way in which agents discount past information. We choose the following two parameters of $\gamma: 0.001$ and 0.004 . Table 8 reports the relative standard derivations of labour market variables under the two alternative parameterisations. Our simulations show that the values of the gain parameter have very little influence in terms of the statistical properties of the simulated data because this parameter only affects the amount of time it takes for the model to equilibrium but does not alter the overall dynamic properties of labour market variables. A smaller gain parameter indicates that agents put more weight on past data relative to current data to update beliefs, which means that the time it takes for the effects of TFP innovations to vanish from agents' information set is longer. The amplification results are therefore independent of the choice of the parameter $\gamma$.

\section{Euler Equation}

There is an alternative form of learning widely used in the literature (for example, see Bullard and Mitra (2002) and Evans and Honkapohja (2006)) where agents make onestep ahead forecasts (as opposed to making forecasts over the infinite horizon, also known as Infinite Horizon (IH) learning). This approach (also known as Euler-Equation (EE) learning) would take equation (8) as the behavioural rule of the household and equation (18) as the behavioural rule of the firm. Households recognise that consumption at any point of time depends (only) on the employment rate and use this rule to forecast onestep ahead consumption. Firms, on the other hand, forecast employment, wages and 
Table 8: Alternative Parametrisation

\begin{tabular}{ccccccc}
\hline \hline & $\sigma_{n} / \sigma_{y}$ & $\sigma_{v} / \sigma_{y}$ & $\sigma_{u} / \sigma_{y}$ & $\sigma_{\theta} / \sigma_{y}$ & $\sigma_{c} / \sigma_{y}$ & $\sigma_{w} / \sigma_{y}$ \\
\hline Baseline & 0.50 & 10.31 & 7.97 & 17.91 & 0.93 & 1.94 \\
$\mathrm{RE}$ & 0.03 & 0.50 & 0.43 & 0.91 & 1.01 & 0.98 \\
\hline Alternative & parameterisation of $\gamma$ \\
Learning $(\gamma=0.001)$ & 0.50 & 10.73 & 7.88 & 17.47 & 0.93 & 1.96 \\
Learning $(\gamma=0.004)$ & 0.48 & 10.71 & 7.59 & 16.96 & 0.94 & 1.89 \\
\hline \multicolumn{7}{c}{ Alternative parameterisation of $\alpha$} \\
Learning $(\alpha=0.67)$ & 0.45 & 10.12 & 7.09 & 15.83 & 0.94 & 2.42 \\
\hline
\end{tabular}

Notes. Relative standard deviations this table correspond to the quarterly simulated series expressed in percentage deviations from the steady state values under combinations of alternative parameterisations $(\gamma$ and $\alpha)$.

Table 9: EE Learning and Amplification

\begin{tabular}{lcccccc}
\hline \hline & $\sigma_{n} / \sigma_{y}$ & $\sigma_{v} / \sigma_{y}$ & $\sigma_{u} / \sigma_{y}$ & $\sigma_{\theta} / \sigma_{y}$ & $\sigma_{c} / \sigma_{y}$ & $\sigma_{w} / \sigma_{y}$ \\
\hline $\mathrm{RE}$ & 0.03 & 0.50 & 0.43 & 0.91 & 1.01 & 0.98 \\
EE Learning & 0.17 & 3.08 & 2.60 & 5.58 & 0.98 & 1.26 \\
IH Learning & 0.50 & 10.31 & 7.97 & 17.91 & 0.93 & 1.94 \\
\hline
\end{tabular}

Notes. Relative standard deviations in this table correspond to the quarterly simulated series expressed in percentage deviations from the steady state values.

labour market tightness next period based on the last available data on employment (see appendix $\mathrm{C}$ for details).

For completeness, we now compare the performance of the baseline model against the model with EE learning. Table 9 shows that EE learning, which requires agents to make one-step ahead forecasts as in the model with RE beliefs, cannot match the amplification generated under IH learning. EE learning, however, generates much more amplification than the RE model. This shows that adaptive learning is important for amplification and, in particular, the type of learning adopted by agents is relevant for the magnitude of amplification. The reason behind this finding has to do with the fact that the extent of overoptimism on the part of firms when posting vacancies is greater in the IH learning model than the model under EE learning.

Figure 2 shows the responses of output and labour market variables to an increase in productivity shock under EE learning. The degree of response of the variables under EE learning is smaller relative to IH learning but larger than under RE.

\section{Conclusion}

We develop a highly stylised model of the labour market with adaptive learning and show that the model is able to match US labour data remarkably well in terms of its amplification. In the standard search and matching model the vacancy positing decision depends crucially on what firms expect the present discounted value of profits per hire to be. We relax the assumptions of Rational Expectations (RE) to study the role of 
expectation formation on job creation. We make the assumption that agents run simple regressions using the (un)employment rate as the main regressor, and update their beliefs as new information becomes available in order to make infinite horizon forecasts about future wages and to choose how many vacancies to post.

In particular, we find that Total Factor Productivity (TFP) innovations under learning can generate a greater incentive for vacancy creation relative to RE. A TFP innovation under learning increases the firms' present discounted value of profits per hire (i.e., firms become overoptimistic). Thus, we find that expectation formation has a central role to play in providing a solution to unemployment volatility puzzle. Our solution relies on standard assumptions about the general structure of the model: a) wages for newly hired workers are cyclical and b) our calibration ensures that our results are not driven by the HM strategy. 


\section{References}

Alves, S. A. L. (2012). Trend inflation and the unemployment volatility puzzle. Working Papers Series 277, Central Bank of Brazil, Research Department.

Andolfatto, D. (1996). Business cycles and labor-market search. American Economic Review, 86(1):112-32.

Barnichon, R. (2010). Building a composite help-wanted index. Economics Letters, 109(3):175-178.

Blanchard, O. and Gali, J. (2010). Labor markets and monetary policy: A New Keynesian model with unemployment. American Economic Journal: Macroeconomics, 2(2):1-30.

Branch, W. (2004). Restricted perceptions equilibria and learning in macroeconomics. In Colander (2004).

Branch, W. A. and Evans, G. W. (2006a). Intrinsic heterogeneity in expectation formation. Journal of Economic Theory, 127(1):264-295.

Branch, W. A. and Evans, G. W. (2006b). A simple recursive forecasting model. Economics Letters, 91(2):158-166.

Bullard, J. and Mitra, K. (2002). Learning about monetary policy rules. Journal of Monetary Economics, 49(6):1105-1129.

Carceles-Poveda, E. and Giannitsarou, C. (2008). Asset pricing with adaptive learning. Review of Economic Dynamics, 11:629-651.

Cho, I.-K., Williams, N., and Sargent, T. J. (2002a). Escaping nash inflation. Review of Economic Studies, 69(1):1-40.

Cho, I.-K., Williams, N., and Sargent, T. J. (2002b). Escaping nash inflation. Review of Economic Studies, 69:1-40.

Christoffel, K. and Kuester, K. (2008). Resuscitating the wage channel in models with unemployment fluctuations. Journal of Monetary Economics, 55(5):865-887.

Cogley, T. and Sargent, T. J. (2008). Anticipated Utility And Rational Expectations As Approximations Of Bayesian Decision Making. International Economic Review, 49(1):185-221.

Colander, D., editor (2004). Post Walrasian Macroeconomics: Beyond the Dynamic Stochastic General Equilibrium Model. Cambridge University Press, Cambridge.

Colciago, A. and Rossi, L. (2011). Endogenous market structures and labor market dynamics (new version). Quaderni di Dipartimento 155, University of Pavia, Department of Economics and Quantitative Methods.

Costain, J. S. and Reiter, M. (2008). Business cycles, unemployment insurance, and the calibration of matching models. Journal of Economic Dynamics and Control, $32(4): 1,120-55$.

Davis, S., Haltiwanger, J., and Schuh, S. (1996). Job creation and destruction. MIT Press. 
Del Negro, M. and Eusepi, S. (2011). Fitting observed inflation expectations. Journal of Economic Dynamics and Control, 35(12):2105-2131.

den Haan, W. J., Ramey, G., and Watson, J. (2000). Job destruction and the experiences of displaced workers. Carnegie-Rochester Conference Series on Public Policy, 52(1):87128.

Di Pace, F. and Faccini, R. (2012). Deep habits and the cyclical behaviour of equilibrium unemployment and vacancies. Journal of Economic Dynamics and Control, 36(2):183200.

Ellison, M. and Yates, T. (2007). Escaping volatile inflation. Journal of Money, Credit and Banking, 39:981-993.

Eusepi, S. and Preston, B. (2011). Expectations, learning, and business cycle fluctuations. American Economic Review, 101(6):2844-72.

Evans, G. and Honkapohja, S. (2001). Learning and Expectations in Macroeconomics (Frontiers of Economic Research). Princeton.

Evans, G. W. and Honkapohja, S. (2003). Expectations and the Stability Problem for Optimal Monetary Policies. Review of Economic Studies, 70(4):807-824.

Evans, G. W. and Honkapohja, S. (2006). Monetary policy, expectations and commitment. Scandinavian Journal of Economics, 108:15-38.

Gertler, M., Sala, L., and Trigari, A. (2008). An estimated monetary DSGE model with unemployment and staggered nominal wage bargaining. Journal of Money, Credit and Banking, 40(8):1,713-64.

Gertler, M. and Trigari, A. (2009). Unemployment fluctuations with staggered Nash wage bargaining. Journal of Political Economy, 117(1):38-86.

Gomes, P. (2011). Fiscal policy and the labour market: the effects of public sector employment and wages. European Economy - Economic Papers 439, Directorate General Economic and Monetary Affairs (DG ECFIN), European Commission.

Guerrieri, V. (2008). Heterogeneity, job creation and unemployment volatility. Scandinavian Journal of Economics, 109(4):667-693.

Haefke, C., Sonntag, M., and van Rens, T. (2013). Wage rigidity and job creation. Journal of Monetary Economics, 60(8).

Hagedorn, M. and Manovskii, I. (2008). The cyclical behavior of equilibrium unemployment and vacancies revisited. American Economic Review, 98(4):1,692-706.

Hall, R. E. (2005). Employment fluctuations with equilibrium wage stickiness. American Economic Review, 95(1):50-65.

Heemeijer, P., Hommes, C., Sonnemans, J., and Tuinstra, J. (2009). Price stability and volatility in markets with positive and negative expectations feedback: An experimental investigation. Journal of Economic Dynamics and Control, 33(5):1052-1072. 
Hertweck, M. S. (2013). Strategic wage bargaining, labor market volatility, and persistence. The B.E. Journal of Macroeconomics, 13(1):27.

Hommes, C., Sonnemans, J., Tuinstra, J., and van de Velden, H. (2005). Coordination of Expectations in Asset Pricing Experiments. Review of Financial Studies, 18(3):955-980.

Hommes, C. and Zhu, M. (2014). Behavioral learning equilibria. Journal of Economic Theory, 150(C):778-814.

Hosios, A. J. (1990). On the efficiency of matching and related models of search and unemployment. Review of Economic Studies, 57(2):279-98.

Huang, K., Liu, Z., and Zha, T. (2009). Learning, adaptive expectations and technology shocks. Economic Journal, 119:377-405.

Keynes, J. M. (1936). The General Theory of Employment, Interest and Money. New York: MacMillan.

Kreps, D. M. (1998). Anticipated utility and dynamic choice. pages 242-274. Cambridge University Press, Cambridge.

McGough, B. (2006). Shocking escapes. Economic Journal, 116:507-528.

Menzio, G. (2005). High frequency wage rigidity. Technical report, mimeo.

Menzio, G. and Shi, S. (2011). Efficient search on the job and the business cycle. Journal of Political Economy, 119(3):468 - 510.

Milani, F. (2007). Expectations, learning and macroeconomic persistence. Journal of Monetary Economics, 54(7):2065-2082.

Milani, F. (2011). Expectation shocks and learning as drivers of the business cycle. Economic Journal, 121:379-401.

Mitra, K., Evans, G. W., and Honkapohja, S. (2013). Policy change and learning in the rbc model. Journal of Economic Dynamics and Control, 37(10):1947-1971.

Mortensen, D. and Nagypal, E. (2007). More on unemployment and vacancy fluctuations. Review of Economic Dynamics, 10(3):327-347.

Mortensen, D. T. and Pissarides, C. A. (1994). Job creation and job destruction in the theory of unemployment. Review of Economic Studies, 61(3):397-415.

Orphanides, A. and Williams, J. C. (2007). Robust monetary policy with imperfect knowledge. Journal of Monetary Economics, 54(5):1406-1435.

Petrongolo, B. and Pissarides, C. A. (2001). Looking into the black box: a survey of the matching function. Journal of Economic Literature, 39(2):390-431.

Petrosky-Nadeau, N. (2013). Credit, vacancies and unemployment fluctuations. Review of Economic Dynamics. Forthcoming.

Petrosky-Nadeau, N. and Wasmer, E. (2013). The cyclical volatility of labor markets under frictional financial markets. American Economic Journal: Macroeconomics, 5(1):193221. 
Pigou, A. C. (1927). Industrial Fluctuations. London: MacMillan.

Pissarides, C. A. (2009). The unemployment volatility puzzle: is wage stickiness the answer? Econometrica, 77:1,339-369.

Preston, B. (2005). Learning about monetary policy rules when long-horizon expectations matter. International Journal of Central Banking, 1(2).

Preston, B. (2006). Adaptive learning, forecast-based instrument rules and monetary policy. Journal of Monetary Economics, 53(3):507-535.

Preston, B. (2008). Adaptive learning and the use of forecasts in monetary policy. Journal of Economic Dynamics and Control, 32(11):3661-3681.

Quadrini, V. and Trigari, A. (2008). Public employment and the business cycle. Scandinavian Journal of Economics, 109(4):723-742.

Reiter, M. (2007). Embodied technical change and the fluctuations of unemployment and wages. The Scandinavian Journal of Economics, 109(4):695-721.

Robin, J.-M. (2011). On the dynamics of unemployment and wage distributions. Econometrica, 79(5):1327-1355.

Sargent, T. (1999a). The Conquest of American Inflation. Princeton University Press.

Sargent, T. J. (1999b). The Conquest of American Inflation. Princeton University Press, Princeton NJ.

Shimer, R. (2005). The cyclical behavior of equilibrium unemployment and vacancies. American Economic Review, 95(1):25-49.

Shimer, R. (2010). Labor Markets and Business Cycles (Crei Lectures in Macroeconomics). Princeton University Press.

Slobodyan, S. and Wouters, R. (2012a). Learning in a Medium-Scale DSGE Model with Expectations Based on Small Forecasting Models. American Economic Journal: Macroeconomics, 4(2):65-101.

Slobodyan, S. and Wouters, R. (2012b). Learning in an estimated medium-scale DSGE model. Journal of Economic Dynamics and Control, 36(1):26-46.

Trigari, A. (2006). The role of search frictions and bargaining for inflation dynamics. Working Papers 304, Innocenzo Gasparini Institute for Economic Research, Bocconi University. 


\section{A Wage Bargaining}

The surplus of the worker working for firm $f, \mathcal{W}_{t}^{f}$, is given by the marginal value of employment, equation (40), expressed in terms of goods

$$
\mathcal{W}_{t}^{f}=\frac{\partial \mathcal{H}\left(s_{t-1}, n_{t}\right)}{\partial n_{t}^{f}} c_{t}
$$

Thus,

$$
\mathcal{W}_{t}^{f}=w_{t}^{f}-\chi c_{t}+\left[1-\rho-p\left(\theta_{t}\right)\right] r_{t}^{-1} \tilde{E}_{t} \mathcal{W}_{t+1}^{f}
$$

The negotiated wage $w_{t}^{f}$ is set to maximise the joint surplus of a match between a worker and a firm,

$$
\arg \max _{w_{t}^{f}}\left(\mathcal{W}_{t}^{f}\right)^{\xi}\left(\mathcal{V}_{t}^{f}\right)^{1-\xi}
$$

where $\xi \in(0,1)$ denotes the workers' bargaining power or the share of the surplus the worker is able to take. The first order condition of this problem is given by

$$
(1-\xi) \mathcal{W}_{t}^{f}=\xi \mathcal{V}_{t}^{f}
$$

Substituting for equation (17) and (40) gives the negotiated wage $w_{t}^{f}$

$$
\begin{aligned}
w_{t}^{f} & =(1-\xi)\left\{\chi c_{t}-\left[1-\rho-p\left(\theta_{t}\right)\right] r_{t}^{-1} \tilde{E}_{t} \mathcal{W}_{t+1}^{f}\right\}+ \\
& +\xi\left[\alpha z_{t}^{f}\left(n_{t}^{f}\right)^{\alpha-1}+(1-\rho) r_{t}^{-1} \tilde{E}_{t}^{f} \mathcal{V}_{t+1}^{f}\right]
\end{aligned}
$$

Because of continuous re-negotiation, we assume that the first order condition also holds for subjective expectations

$$
(1-\xi) \tilde{E}_{t} \mathcal{W}_{t+1}^{f}=\xi \tilde{E}_{t}^{f} \mathcal{V}_{t+1}^{f}
$$

to get the following expression

$$
w_{t}^{f}=(1-\xi)\left[\chi c_{t}+p\left(\theta_{t}\right) r_{t}^{-1} \tilde{E}_{t} \mathcal{W}_{t+1}^{h, f}\right]+\xi \alpha z_{t}^{f}\left(n_{t}^{f}\right)^{\alpha-1} .
$$

Using (43) yields

$$
w_{t}^{f}=(1-\xi) \chi c_{t}+\xi\left[\alpha z_{t}^{f}\left(n_{t}^{f}\right)^{\alpha-1}+p\left(\theta_{t}\right) r_{t}^{-1} \tilde{E}_{t}^{f} \mathcal{V}_{t+1}^{h, f}\right]
$$

Substituting (16) gives

$$
w_{t}^{f}=(1-\xi) \chi c_{t}+\xi\left[\alpha z_{t}^{f}\left(n_{t}^{f}\right)^{\alpha-1}+p\left(\theta_{t}\right) \frac{\kappa}{q\left(\theta_{t}\right)}\right]
$$

Rearranging gives expression (21) in the main text

$$
w_{t}^{f}=\xi \alpha z_{t}^{f}\left(n_{t}^{f}\right)^{\alpha-1}+\xi \kappa \theta_{t}+(1-\xi) \chi c_{t} .
$$




\section{B IH learning}

We define the following expressions

$$
\begin{aligned}
\bar{n}_{t}^{e} & =\frac{b_{n}}{1-a_{n n}}, \\
\bar{w}_{t}^{e} & =b_{w}+a_{w n} \bar{n}_{t}^{e} \\
\bar{r}_{t}^{e} & =b_{r}+a_{r n} \bar{n}_{t}^{e} \\
\bar{\pi}_{t}^{e} & =b_{\pi}+a_{\pi} \bar{n}_{t}^{e},
\end{aligned}
$$

where $\bar{n}_{t}^{e}, \bar{w}_{t}^{e}, \bar{r}_{t}^{e}$ and $\bar{\pi}_{t}^{e}$ are the agents' perceived steady state values at period $t$. We also define as deviations of the variables from the perceived steady state

$$
\begin{aligned}
\widehat{n}_{t}^{e} & =n_{t}-\bar{n}_{t}^{e}, \\
\widehat{w}_{t}^{e} & =w_{t}-\bar{w}_{t}^{e}, \\
\widehat{r}_{t}^{e} & =r_{t}-\bar{r}_{t}^{e}, \\
\widehat{\pi}_{t}^{e} & =\pi_{t}-\bar{\pi}_{t}^{e} .
\end{aligned}
$$

In the model with incomplete knowledge, the Perceived Laws of Motion (PLMs) are

$$
\begin{aligned}
\widehat{n}_{t+1}^{e} & =a_{n n} \widehat{n}_{t}^{e}, \\
\widehat{w}_{t}^{e} & =a_{w n} \widehat{n}_{t}^{e}, \\
\widehat{r}_{t}^{e} & =a_{r n} \widehat{n}_{t}^{e}, \\
\widehat{\pi}_{t}^{e} & =a_{\pi n} \widehat{n}_{t}^{e} .
\end{aligned}
$$

Thus, future expectations about employment, wages, interest rates and profits can be written as

$$
\begin{aligned}
\tilde{E}_{t} \widehat{n}_{t+j}^{e} & =a_{n n}^{j} \widehat{n}_{t}^{e}, \\
\tilde{E}_{t} \widehat{w}_{t+j}^{e} & =a_{w n} a_{n n}^{j} \widehat{n}_{t}^{e}, \\
\tilde{E}_{t} \widehat{r}_{t+j}^{e} & =a_{r n} a_{n n}^{j} \widehat{n}_{t}^{e}, \\
\tilde{E}_{t} \widehat{\pi}_{t+j}^{e} & =a_{\pi n} a_{n n}^{j} \widehat{n}_{t}^{e} .
\end{aligned}
$$

We are now ready to derive the behavior rules of households and firm including the forms of the sums. Firstly, we derive the firms' vacancy posting rule, equation (25). The linearisation of equations (15) and (18) read

$$
\widehat{n}_{t+1}^{f}=(1-\rho) \widehat{n}_{t}^{f}+\bar{v} \widehat{q}_{t}+\bar{q} \widehat{v}_{t}^{f}
$$

and

$$
\begin{aligned}
-\frac{\kappa}{\bar{q}^{2}} \widehat{q}_{t}= & -\frac{\alpha \bar{z} \bar{n}^{\alpha-1}-\bar{w}}{\bar{r}^{2}} \widehat{r}_{t}+\frac{1}{\bar{r}} \alpha \bar{z}(\alpha-1) \bar{n}^{\alpha-2} \widehat{n}_{t+1}^{f}+\frac{1}{\bar{r}} \alpha \bar{n}^{\alpha-1} \widehat{z}_{t+1}-\frac{1}{\bar{r}} \widehat{w}_{t+1}^{f}+ \\
& +\sum_{j=2}^{\infty}(1-\rho)^{j-1} \beta^{j} \tilde{E}_{t}^{f}\left[\alpha \bar{z}(\alpha-1) \bar{n}^{\alpha-2} \widehat{n}_{t+j}^{f}+\alpha \bar{n}^{\alpha-1} \widehat{z}_{t+j}-\widehat{w}_{t+j}^{f}\right]- \\
& -\left(\alpha \bar{z} \bar{n}^{\alpha-1}-\bar{w}\right) \beta^{2} \sum_{j=2}^{\infty}(1-\rho)^{j-1} \beta^{j-1} \sum_{i=1}^{j} \tilde{E}_{t}^{f} \widehat{r}_{t+i-1}
\end{aligned}
$$


respectively. Combining the above expressions to eliminate $\widehat{n}_{t+1}$, we have equation (25) in the main text

$$
\begin{aligned}
\bar{\lambda}_{1} \bar{q} \widehat{v}_{t}^{f}= & \beta \bar{\lambda}_{1}(1-\rho) \widehat{n}_{t}^{f}+\left[\frac{\kappa}{\bar{q}^{2}}+\beta \bar{\lambda}_{1} \bar{v}\right] \widehat{q}_{t}+\sum_{j=2}^{\infty}(1-\rho)^{j-1} \beta^{j} \tilde{E}_{t}^{f} \bar{\lambda}_{1} \widehat{n}_{t+j}^{f}+ \\
& +\sum_{j=1}^{\infty}(1-\rho)^{j-1} \beta^{j} \tilde{E}_{t}^{f}\left[\bar{\lambda}_{2} \widehat{z}_{t+j}-\widehat{w}_{t+j}^{f}-\left(\bar{z} \bar{\lambda}_{2}-\bar{w}\right) \beta \sum_{i=0}^{j-1} \widehat{r}_{t+i}\right]
\end{aligned}
$$

where $\bar{\lambda}_{1} \equiv \alpha(\alpha-1) \bar{z} \bar{n}^{\alpha-2}, \bar{\lambda}_{2} \equiv \alpha \bar{n}^{\alpha-1}$. We then integrate expression (25) over $f$ to get expression (26) in the main text

$$
\bar{\lambda}_{1} \bar{q} \widehat{v}_{t}=\beta \bar{\lambda}_{1}(1-\rho) \widehat{n}_{t}+\left[\frac{\kappa}{\bar{q}^{2}}+\beta \bar{\lambda}_{1} \bar{v}\right] \widehat{q}_{t}+\mathcal{S}_{z, t}^{F}+\mathcal{S}_{n, t}^{F}-\mathcal{S}_{w, t}^{F}-\mathcal{S}_{r, t}^{F},
$$

where

$$
\begin{aligned}
& \mathcal{S}_{z, t}^{F}=\sum_{j=1}^{\infty}(1-\rho)^{j-1} \beta^{j} \bar{\lambda}_{2} \tilde{E}_{t} \widehat{z}_{t+j}=\sum_{j=1}^{\infty}(1-\rho)^{j-1} \beta^{j} \bar{\lambda}_{2} \varrho^{j} \widehat{z}_{t}=\frac{\beta \varrho \bar{\lambda}_{2}}{1-(1-\rho) \beta \varrho} \widehat{z}_{t}, \\
& \mathcal{S}_{w, t}^{F}=\sum_{j=1}^{\infty}(1-\rho)^{j-1} \beta^{j} \tilde{E}_{t} \widehat{w}_{t+j}= \\
&=\sum_{j=1}^{\infty}(1-\rho)^{j-1} \beta^{j}\left(\bar{w}_{t}^{e}-\bar{w}\right)+\sum_{j=1}^{\infty}(1-\rho)^{j-1} \beta^{j} \tilde{E}_{t} \widehat{w}_{t+j}^{e}= \\
&=\frac{\beta\left(\bar{w}_{t}^{e}-\bar{w}\right)}{1-\beta(1-\rho)}+a_{w n} \sum_{j=1}^{\infty} \beta^{j}(1-\rho)^{j-1} a_{n n}^{j} \widehat{n}_{t}^{e}= \\
&=\frac{\beta\left(\bar{w}_{t}^{e}-\bar{w}\right)}{1-\beta(1-\rho)}+a_{w n} \frac{\beta a_{n n}}{1-\beta(1-\rho) a_{n n}} \widehat{n}_{t}^{e}, \\
& \mathcal{S}_{n, t}^{F}=\sum_{j=2}^{\infty}(1-\rho)^{j-1} \beta^{j} \bar{\lambda}_{1} \tilde{E}_{t} \widehat{n}_{t+j}= \\
&=\sum_{j=2}^{\infty}(1-\rho)^{j-1} \beta^{j} \bar{\lambda}_{1}\left(\bar{n}_{t}^{e}-\bar{n}\right)+\sum_{j=2}^{\infty}(1-\rho)^{j-1} \beta^{j} \bar{\lambda}_{1} \tilde{E}_{t} \widehat{n}_{t+j}^{e}= \\
&= \frac{\bar{\lambda}_{1} \beta^{2}(1-\rho)\left(\bar{n}_{t}^{e}-\bar{n}_{)}\right.}{1-\beta(1-\rho)}+\sum_{j=2}^{\infty}(1-\rho)^{j-1} \beta^{j} \bar{\lambda}_{1} a_{n n}^{j} \widehat{n}_{t}^{e}= \\
&= \frac{\bar{\lambda}_{1} \beta^{2}(1-\rho)\left(\bar{n}_{t}^{e}-\bar{n}_{n}\right)}{1-\beta(1-\rho)}+\frac{\beta^{2}(1-\rho) a_{n n}^{2} \bar{\lambda}_{1}}{1-\beta(1-\rho) a_{n n}} \widehat{n}_{t}^{e} .
\end{aligned}
$$

To compute $\mathcal{S}_{r, t}^{F}$ firstly note that

$$
\sum_{j=1}^{\infty}(1-\rho)^{j} \beta^{j} j=\frac{\beta(1-\rho)}{[1-\beta(1-\rho)]^{2}}
$$

and that

$$
\begin{aligned}
\sum_{j=1}^{\infty}(1-\rho)^{j} \beta^{j} \frac{a_{n n}-a_{n n}^{j+1}}{1-a_{n n}} & =\frac{\beta(1-\rho) a_{n n}}{\left(1-a_{n n}\right)[1-\beta(1-\rho)]}-\frac{\beta(1-\rho) a_{n n}^{2}}{\left(1-a_{n n}\right)\left[1-\beta(1-\rho) a_{n n}\right]}= \\
& =\frac{\beta(1-\rho) a_{n n}}{\left[1-\beta(1-\rho) a_{n n}\right][1-\beta(1-\rho)]} .
\end{aligned}
$$


Thus,

$$
\begin{aligned}
\mathcal{S}_{r, t}^{F} & =\bar{\lambda}_{3} \sum_{j=1}^{\infty}(1-\rho)^{j-1} \beta^{j+1} \sum_{i=0}^{j-1} \tilde{E}_{t} \widehat{r}_{t+i}= \\
& =\bar{\lambda}_{3} \sum_{j=1}^{\infty}(1-\rho)^{j-1} \beta^{j+1} \widehat{r}_{t}+\bar{\lambda}_{3} \sum_{j=1}^{\infty}(1-\rho)^{j} \beta^{j+2} \sum_{i=1}^{j} \tilde{E}_{t} \widehat{r}_{t+i}= \\
& =\frac{\bar{\lambda}_{3} \beta^{2}}{1-\beta(1-\rho)} \widehat{r}_{t}+\bar{\lambda}_{3} \sum_{j=1}^{\infty}(1-\rho)^{j} \beta^{j+2}\left(\bar{r}_{t}^{e}-\bar{r}\right) j+\bar{\lambda}_{3} \sum_{j=1}^{\infty}(1-\rho)^{j} \beta^{j+2} \sum_{i=1}^{j} \tilde{E}_{t} \widehat{r}_{t+i}^{e}= \\
& =\frac{\bar{\lambda}_{3} \beta^{2}}{1-\beta(1-\rho)} \widehat{r}_{t}+\frac{\bar{\lambda}_{3} \beta^{3}(1-\rho)\left(\bar{r}_{t}^{e}-\bar{r}\right)}{[1-\beta(1-\rho)]^{2}}+\bar{\lambda}_{3} \sum_{j=1}^{\infty}(1-\rho)^{j} \beta^{j+2} \sum_{i=1}^{j} a_{r n} a_{n n}^{i} \widehat{n}_{t}^{e}= \\
& =\frac{\bar{\lambda}_{3} \beta^{2}}{1-\beta(1-\rho)} \widehat{r}_{t}+\frac{\bar{\lambda}_{3} \beta^{3}(1-\rho)\left(\bar{r}_{t}^{e}-\bar{r}\right)}{[1-\beta(1-\rho)]^{2}}+\bar{\lambda}_{3} \sum_{j=1}^{\infty}(1-\rho)^{j} \beta^{j+2} a_{r n} \frac{a_{n n}-a_{n n}^{j+1}}{1-a_{n n}} \widehat{n}_{t}^{e}= \\
& =\frac{\bar{\lambda}_{3} \beta^{2}}{1-\beta(1-\rho)} \widehat{r}_{t}+\frac{\bar{\lambda}_{3} \beta^{3}(1-\rho)\left(\bar{r}_{t}^{e}-\bar{r}\right)}{[1-\beta(1-\rho)]^{2}}+\frac{\bar{\lambda}_{3} \beta^{3}(1-\rho) a_{r n} a_{n n}}{\left[1-\beta(1-\rho) a_{n n}\right][1-\beta(1-\rho)]} \widehat{n}_{t}^{e},
\end{aligned}
$$

where $\bar{\lambda}_{3} \equiv \alpha \bar{z} \bar{n}^{\alpha-1}-\bar{w}$.

Now we compute the sums in the household's consumption behavioral rule. Recall the linearised life-time budget constraint, equation (23), in the main text,

$$
\frac{\widehat{c}_{t}}{1-\beta}=\bar{n} \widehat{w}_{t}+\bar{w} \widehat{n}_{t}+\widehat{\pi}_{t}+\mathcal{S}_{w, t}^{H}+\mathcal{S}_{n, t}^{H}+\mathcal{S}_{\pi, t}^{H}-\mathcal{S}_{r, t}^{H},
$$

where

$$
\begin{gathered}
\mathcal{S}_{\pi, t}^{H}=\sum_{j=1}^{\infty} \beta^{j} \tilde{E}_{t} \widehat{\pi}_{t+j}=\sum_{j=1}^{\infty} \beta^{j}\left(\bar{\pi}_{t}^{e}-\bar{\pi}\right)+\sum_{j=1}^{\infty} \beta^{j} \tilde{E}_{t} \widehat{\pi}_{t+j}^{e}= \\
=\frac{\beta\left(\bar{\pi}_{t}^{e}-\bar{\pi}\right)}{1-\beta}+a_{\pi n} \sum_{j=1}^{\infty} \beta^{j} a_{n n}^{j} \widehat{n}_{t}^{e}=\frac{\beta\left(\bar{\pi}_{t}^{e}-\bar{\pi}\right)}{1-\beta}+a_{\pi n} \frac{\beta a_{n n}}{1-\beta a_{n n}} \widehat{n}_{t}^{e}, \\
\mathcal{S}_{w, t}^{H}=\sum_{j=1}^{\infty} \beta^{j} \tilde{E}_{t} \bar{n} \widehat{w}_{t+j}=\bar{n} \sum_{j=1}^{\infty} \beta^{j}\left(\bar{w}_{t}^{e}-\bar{w}\right)+\bar{n} \sum_{j=1}^{\infty} \beta^{j} \tilde{E}_{t} \widehat{w}_{t+j}^{e}= \\
=\frac{\beta \bar{n}\left(\bar{w}_{t}^{e}-\bar{w}\right)}{1-\beta}+\bar{n} a_{w n} \sum_{j=1}^{\infty} \beta^{j} a_{n n}^{j} \widehat{n}_{t}^{e}=\frac{\beta \bar{n}\left(\bar{w}_{t}^{e}-\bar{w}\right)}{1-\beta}+\bar{n} a_{w n} \frac{\beta a_{n n}}{1-\beta a_{n n}} \widehat{n}_{t}^{e}, \\
=\sum_{j=1}^{\infty} \beta^{j} \bar{w} \tilde{E}_{t} \widehat{n}_{t+j}=\beta \bar{w} \widehat{n}_{t+1}+\sum_{j=2}^{\infty} \beta^{j} \tilde{E}_{t} \bar{w} \widehat{n}_{t+j}= \\
=\beta \bar{w} \widehat{n}_{t+1}+\bar{w} \sum_{j=2}^{\infty} \beta^{j}\left(\bar{n}_{t}^{e}-\bar{n}\right)+\bar{w} \sum_{j=2}^{\infty} \beta^{j} \tilde{E}_{t} \widehat{n}_{t+j}^{e}= \\
=\beta \bar{w} \widehat{n}_{t+1}+\frac{\beta^{2} \bar{w}\left(\bar{n}_{t}^{e}-\bar{n}\right)}{1-\beta}+\bar{w} \sum_{j=2}^{\infty} \beta^{j} a_{n n}^{j} \widehat{n}_{t}^{e}= \\
=\beta \bar{w} \widehat{n}_{t+1}+\frac{\beta^{2} \bar{w}\left(\bar{n}_{t}^{e}-\bar{n}\right)}{1-\beta}+\bar{w} \frac{\beta^{2} a_{n n}^{2}}{1-\beta a_{n n}} \widehat{n}_{t}^{e}
\end{gathered}
$$




$$
\begin{aligned}
\mathcal{S}_{r, t}^{H}= & (\bar{w} \bar{n}+\bar{\pi}) \sum_{j=1}^{\infty}\left[\beta^{j+1} \sum_{i=0}^{j-1} \tilde{E}_{t} \widehat{r}_{t+i}\right]= \\
= & (\bar{w} \bar{n}+\bar{\pi}) \sum_{j=1}^{\infty} \beta^{j+1} \widehat{r}_{t}+(\bar{w} \bar{n}+\bar{\pi}) \sum_{j=1}^{\infty}\left[\beta^{j+2} \sum_{i=1}^{j} \tilde{E}_{t} \widehat{r}_{t+i}\right]= \\
= & \frac{(\bar{w} \bar{n}+\bar{\pi}) \beta^{2}}{1-\beta} \widehat{r}_{t}+(\bar{w} \bar{n}+\bar{\pi}) \sum_{j=1}^{\infty} \beta^{j+2}\left(\bar{r}_{t}^{e}-\bar{r}\right) j+(\bar{w} \bar{n}+\bar{\Pi}) \sum_{j=1}^{\infty}\left[\beta^{j+2} \sum_{i=1}^{j} \tilde{E}_{t} \widehat{r}_{t+i}^{e}\right]= \\
= & \frac{(\bar{w} \bar{n}+\bar{\pi}) \beta^{2}}{1-\beta} \widehat{r}_{t}+\frac{(\bar{w} \bar{n}+\bar{\pi}) \beta^{3}\left(\bar{r}_{t}^{e}-\bar{r}\right)}{(1-\beta)^{2}}+(\bar{w} \bar{n}+\bar{\Pi}) \sum_{j=1}^{\infty}\left[\beta^{j+2} \sum_{i=1}^{j} a_{r n} a_{n n}^{j} \widehat{n}_{t}^{e}\right]= \\
= & \frac{(\bar{w} \bar{n}+\bar{\pi}) \beta^{2}}{1-\beta} \widehat{r}_{t}+\frac{(\bar{w} \bar{n}+\bar{\pi}) \beta^{3}\left(\bar{r}_{t}^{e}-\bar{r}\right)}{(1-\beta)^{2}}+(\bar{w} \bar{n}+\bar{\Pi}) \sum_{j=1}^{\infty} \beta^{j+2} a_{r n} \frac{a_{n n}-a_{n n}^{j+1}}{1-a_{n n}} \widehat{n}_{t}^{e}= \\
= & \frac{(\bar{w} \bar{n}+\bar{\pi}) \beta^{2}}{1-\beta} \widehat{r}_{t}+\frac{(\bar{w} \bar{n}+\bar{\pi}) \beta^{3}\left(\bar{r}_{t}^{e}-\bar{r}\right)}{(1-\beta)^{2}}+\frac{(\bar{w} \bar{n}+\bar{\pi}) \beta^{3} a_{n n} a_{r n} \widehat{n}_{t}^{e} .}{\left(1-\beta a_{n n}\right)(1-\beta)}
\end{aligned}
$$

\section{EE learning}

Now consider a learning model in which agents only make one-period ahead forecasts. Therefore, households and firms make use of the Euler equation (8) and job creation condition (18) to make their optimal decisions. The whole economic system under EE learning consists of equations (27)-(35) in addition to those two linearised behaviour rules derived here below.

Comparable with the learning rule in our section 2.6, we assume the agents have the following PLMs,

$$
\begin{gathered}
n_{t+1}=b_{n}+a_{n n} n_{t} \\
x_{t}=b_{x}+a_{x n} n_{t}, \quad \text { for } \quad x_{t}=\left\{w_{t}, \theta_{t}, c_{t}\right\} .
\end{gathered}
$$

Let $A_{n, t}=\left(\begin{array}{ll}b_{n} & a_{n n}\end{array}\right)^{\prime}, A_{w, t}=\left(\begin{array}{ll}b_{w} & a_{w n}\end{array}\right)^{\prime}, A_{\theta, t}=\left(\begin{array}{ll}b_{\theta} & a_{\theta n}\end{array}\right)^{\prime}, A_{c, t}=\left(\begin{array}{ll}b_{c} & a_{c n}\end{array}\right)^{\prime}, B_{t}=$ $\left(\begin{array}{ll}1 & n_{t}\end{array}\right)^{\prime}, A_{t}=\left(\begin{array}{llll}A_{n, t} & A_{w, t} & A_{\theta, t} & A_{c, t}\end{array}\right), C_{t}=\left(\begin{array}{llll}n_{t} & w_{t-1} & \theta_{t-1} & c_{t-1}\end{array}\right)^{\prime}$. The RLS formulas for updating beliefs are as follows

$$
\begin{gathered}
A_{t}=A_{t-1}+\gamma R_{t}^{-1} B_{t-1}\left(C_{t}-A_{t-1}^{\prime} B_{t-1}\right)^{\prime}, \\
R_{t}=R_{t-1}+\gamma\left(B_{t-1} B_{t-1}^{\prime}-R_{t-1}\right)
\end{gathered}
$$

We then turn to the derivation of the optimal behavior rules, the counterpart of (24) and (26) as in the IH learning case. Applying the PLMs, we have

$$
\begin{aligned}
& \tilde{E}_{t} n_{t+1}=A_{n, t}^{\prime}\left(\begin{array}{ll}
1 & \bar{n}+\widehat{n}_{t}
\end{array}\right)^{\prime} \\
& \left.\tilde{E}_{t} \widehat{w}_{t+1}=A_{w, t}^{\prime}\left(\begin{array}{ll}
1 & \tilde{E}_{t} n_{t+1}
\end{array}\right)^{\prime}-\bar{w}=A_{w, t}\left(\begin{array}{lll}
1 & A_{n, t}^{\prime}(1 & \bar{n}+\widehat{n}_{t}
\end{array}\right)^{\prime}\right)^{\prime}-\bar{w} \text {, }
\end{aligned}
$$

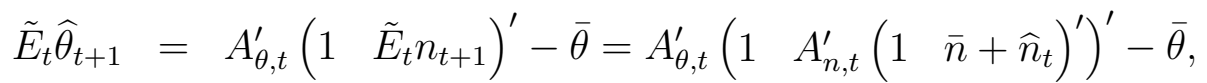

$$
\begin{aligned}
& \tilde{E}_{t} \widehat{c}_{t+1}=A_{c, t}^{\prime}\left(\begin{array}{ll}
1 & \tilde{E}_{t} n_{t+1}
\end{array}\right)^{\prime}-\bar{c}=A_{c, t}^{\prime}\left(\begin{array}{lll}
1 & A_{n, t}^{\prime}\left(\begin{array}{ll}
1 & \bar{n}+\widehat{n}_{t}
\end{array}\right)^{\prime}
\end{array}\right)^{\prime}-\bar{c} .
\end{aligned}
$$

The linearised version of Euler equation reads

$$
\tilde{E}_{t} \widehat{c}_{t+1}=\widehat{c}_{t}+\beta \bar{c} \widehat{r}_{t}
$$


We then have, after substituting for the expectation of $\tilde{E}_{t} \widehat{c}_{t+1}$, that

$$
\left.\widehat{c}_{t}+\beta \bar{c} \widehat{r}_{t}=A_{c, t}^{\prime}\left(\begin{array}{lll}
1 & A_{n, t}^{\prime}(1 & \bar{n}+\widehat{n}_{t}
\end{array}\right)^{\prime}\right)^{\prime}-\bar{c}
$$

which is the consumption rule under EE learning.

The linearized version of vacancy posting condition reads

$-\frac{\kappa}{\beta \bar{q}^{2}} \widehat{q}_{t}+\frac{\kappa}{\bar{q}} \widehat{r}_{t}=\alpha \bar{z}(\alpha-1) \bar{n}^{\alpha-2} \widehat{n}_{t+1}+\alpha \bar{n}^{\alpha-1} \widehat{z}_{t+1}-\tilde{E}_{t} \widehat{w}_{t+1}-\frac{\kappa(1-\rho) \bar{m}(\sigma-1) \bar{\theta}_{t}^{\sigma-2}}{\bar{q}^{2}} \tilde{E}_{t} \widehat{\theta}_{t+1}$.

After substituting the expectations of $\tilde{E}_{t} \widehat{w}_{t+1}$ and $\tilde{E}_{t} \widehat{\theta}_{t+1}$ respectively, we have that

$$
\begin{aligned}
& \alpha \bar{z}(\alpha-1) \bar{n}^{\alpha-2} \widehat{n}_{t+1}+\alpha \bar{n}^{\alpha-1} \varrho \widehat{z}_{t}+\frac{\kappa}{\beta \bar{q}^{2}} \widehat{q}_{t}-\frac{\kappa}{\bar{q}} \widehat{r}_{t}=
\end{aligned}
$$

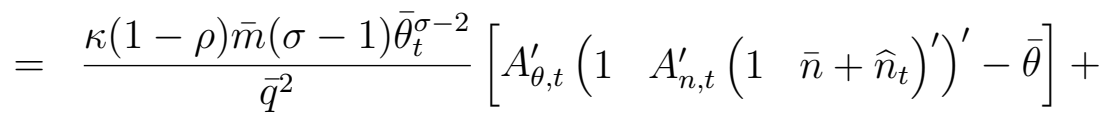

$$
\begin{aligned}
& +A_{w, t}\left(1 \quad A_{n, t}^{\prime}\left(\begin{array}{ll}
1 & \bar{n}+\widehat{n}_{t}
\end{array}\right)^{\prime}\right)^{\prime}-\bar{w}
\end{aligned}
$$

which is the vacancy posting rule. 